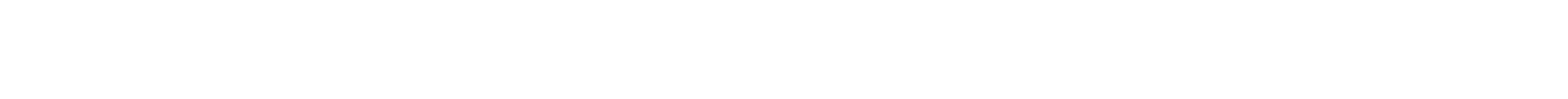

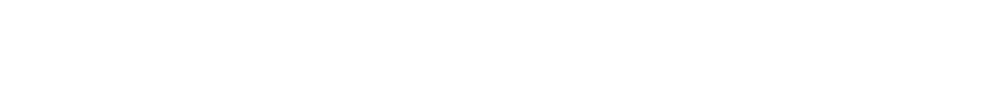

نشول إبرلهيم عبو

$$
\text { جلمعة الموصل التربية }
$$

$$
\text { لئلمعي حلميد الكيمياء }
$$

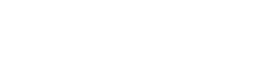

خولة الحمد لَفلبح

قعم الكيمياء

كلية التربية للبنت

جلمعة الموصل

$$
\text { (لُستلم } 19 \text { / } 3 \text { / } 2013 \text { ؛ قُل } 27 \text { / } 5 \text { / } 2013 \text { ) }
$$

تضضمن البحث تحديد مستوى فعالية أنزيم البولي أمين أوكسيديز

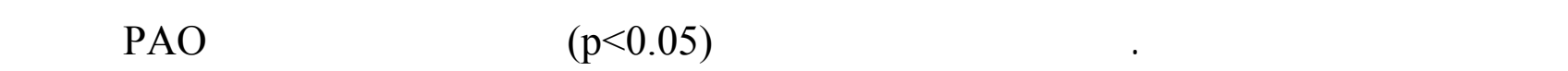

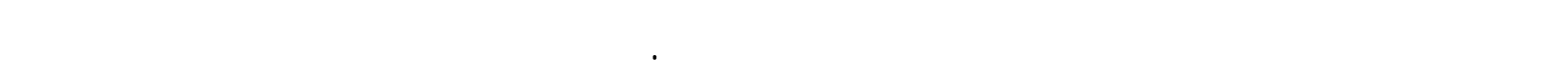

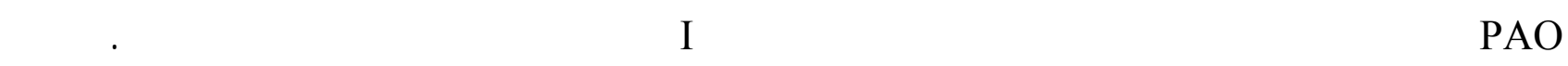

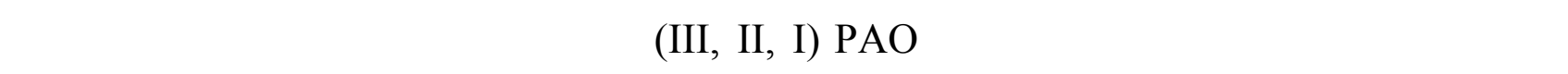
بللسكري أعلاه وفعالية نوعية (وحة أنزيمية املغم بروتين) (0.194،

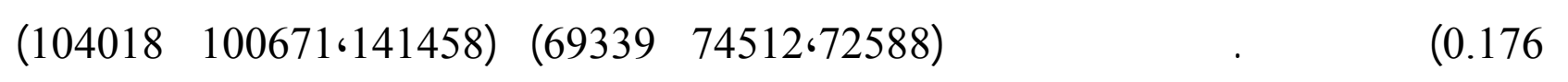

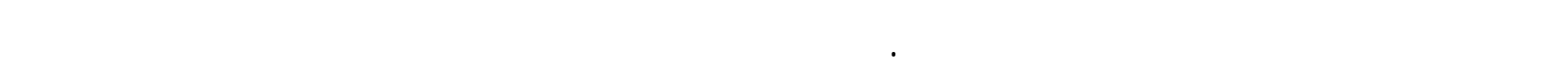

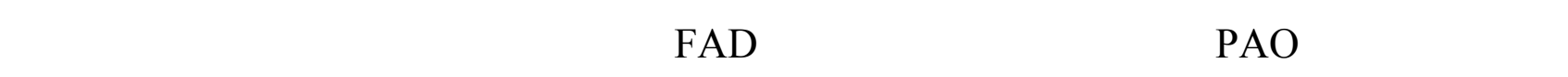
أعلاه.

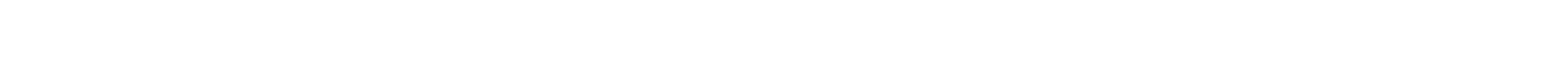

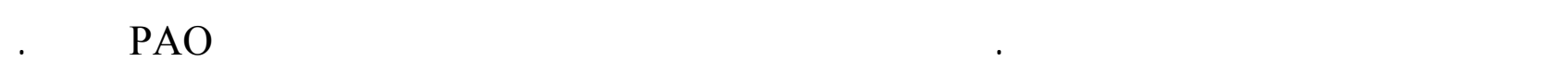

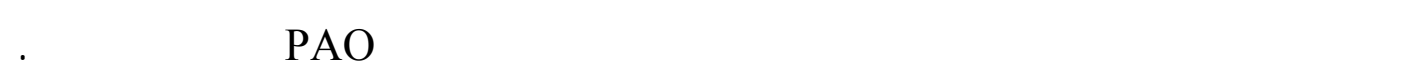
الكاملت الدالة: بولي أمين اوكسيديز، داء السكر، مركبت الثايويوريا. 


$$
\text { خولة لحمد آ فلبح ولخرون }
$$

\title{
Purification of Polyamine Oxidase from Diabetic Type-I Females and Studies of the Inhibitory Effect of some Thiourea Compounds on its Activity
}

\author{
Khawla A. Al-Flayeh \\ Department of Chemistry \\ College of Education for \\ Girls \\ University of Mosul
}

\author{
Ayad S. Hameed \\ Department of Chemistry \\ College of Science
}

University of Tikrit

\author{
Nashwan I. Abo \\ Department of Chemistry \\ College of Education \\ University of Mosul
}

\begin{abstract}
The research included a determination of polyamine oxidase (PAO) activity in normal females and diabetic type I patients. It was found that the activities of PAO in red blood cells $(\mathrm{RBC})$ and plasma in patients were significantly higher than that of normal $(\mathrm{p}<0.05)$.

The partial purification of PAO from RBC of diabetic and normal females were included in this study. This was achieved by using different biochemical techniques. Three proteinous peaks with PAO activities in RBC (I, II, III) from each of normal, diabetic with specific activities (U\mg protein) $(0.194,0.183$ and 0.098$),(0.349,0.237$ and 0.176$)$ were isolated from ion exchange chromatography. Molecular weights (72588, 74512 and 69339), (141458, 100671 and 104018) Da respectively.

This study didn't show the existence of $\mathrm{Cu}^{2+}$ ion as a cofactor for any PAO isoenzyme, but indicated the existence of flavin adenine dinucleotide(FAD) as a cofactor for all PAO isoenzymes.

On the other hand, the research included a preparation of thiourea derivatives of structure analogous to sulfonylurea drugs and containing thiosemicarbazide. Thiosemicarbazide showed an inhibitory effect on partially purified PAO activity. The prepared thiourea derivatives of thiosemicarbazide showed a competitive inhibition of PAO activity.
\end{abstract}

Keywords: Polyamine oxidase, diabetes mellitus, thiourea compounds.

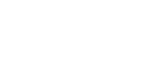

يعمل أنزيم بولي أمين أوكسيديزPolyamine oxidase (PAO على لذك سدة مركب ـات الب -ولي أمـ ــن

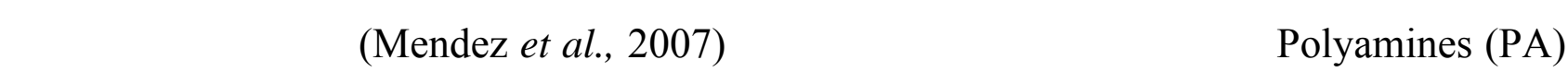
الآتية (Seiler, 1987).

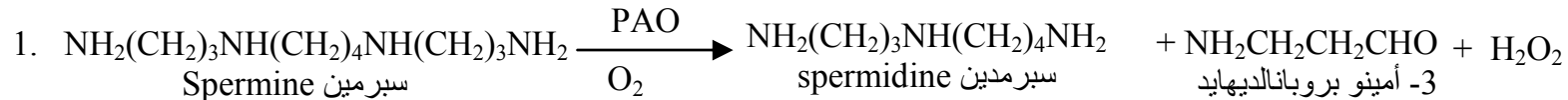

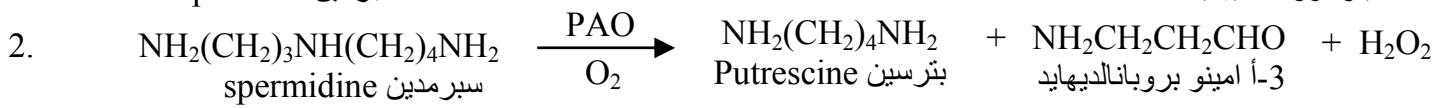




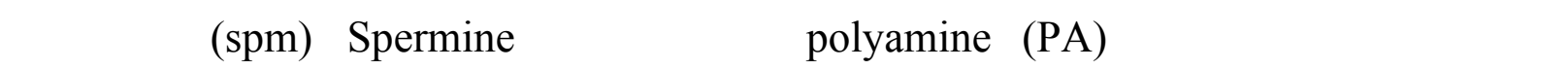
(put) Putrescine والبتريئت عضين (spd) Spermidine المركبت وهي ذات أوزان جزيئية ولطئة في جمبع الخلايا الحية (Wallace et al., 2003)، كما تتولجد في أغلب لنسجة الفقريك. ويحفز أنزيم PAO عملية لكسدة مجموعة الأمن الثانوية لل ـ Spm و

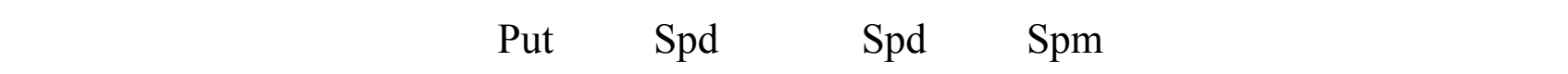

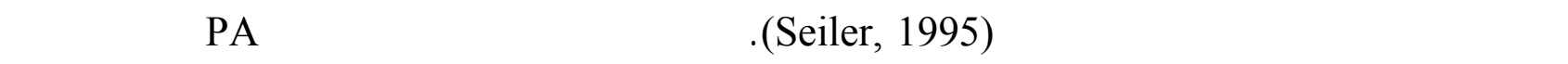

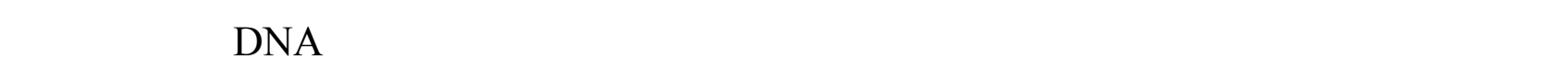

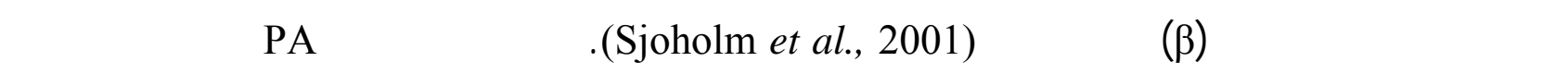

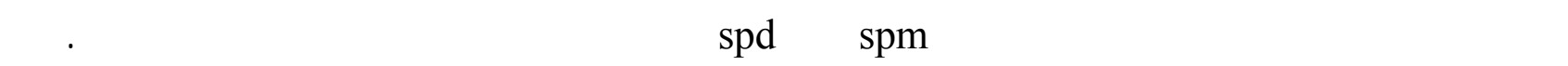

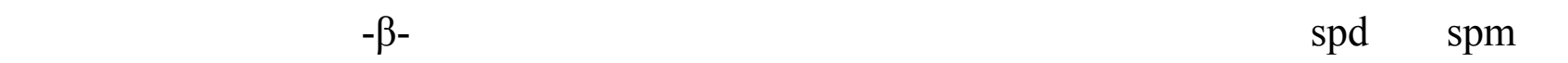

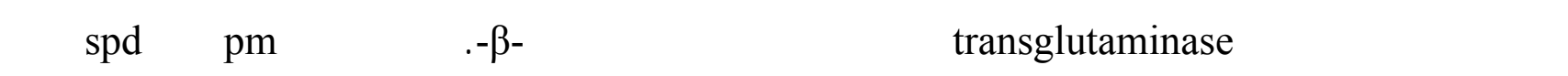

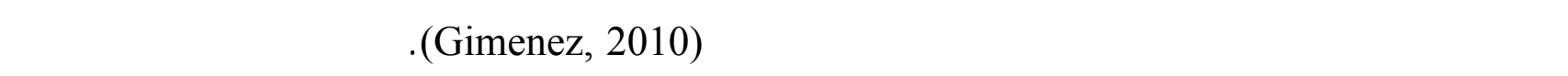

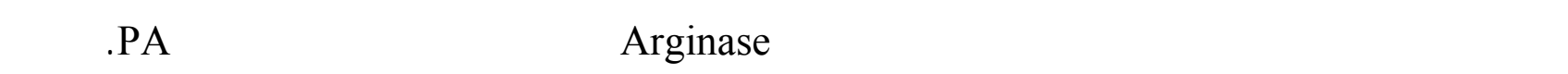

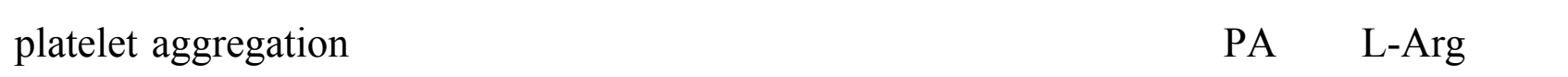

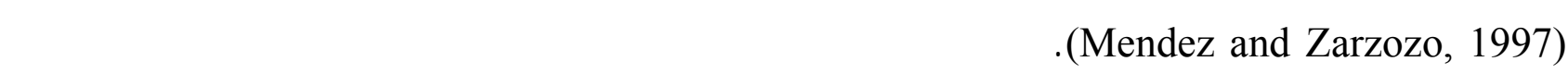

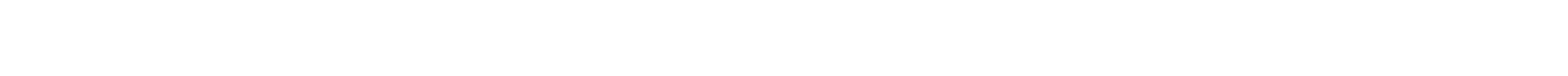

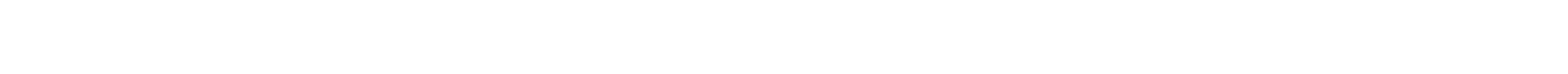

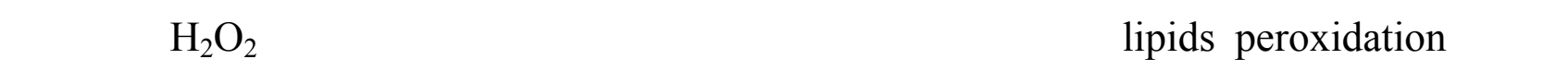
بتولي د الج ذور الح ـرة وبالتالي الاشتراك بإحداث الإجهاد التلكسدي -Murray et al.,2009 ; Murray

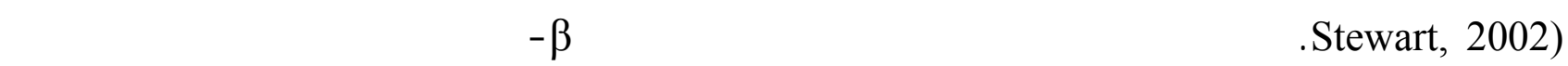
المسببت لحدوث داء للسكر.

\section{المواد طرائق الهل」}

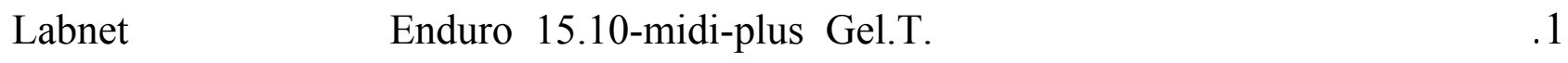

International Inc. الأمريكية في مختبرات كلية التربية الأسلسية

2. مطيف الأشعة تهت الحمراء IR في كلية التربية بلستخدلم قرص KBr Infrared Spectrophotometer. Model Tensor 27 Bruker Co., Germany 


$$
\text { خولة لحمد آ فلبح ولخرون }
$$

3. جهاز التحلل الدقق للعناصر EA-uroVector model : EA 3000 A Italy C.H.N جلمعة آل البي ـا،

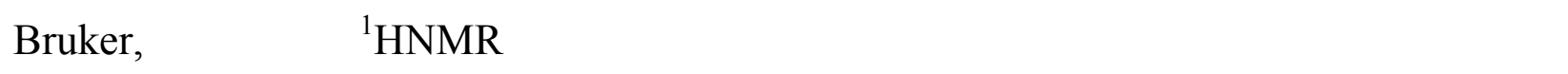

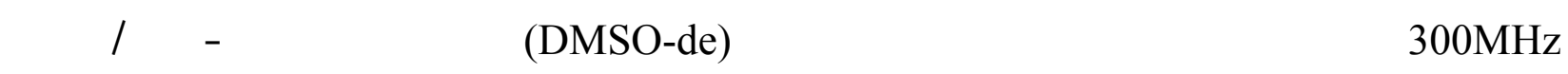
بحوث الميل// المملكة الأرنية الهلثمية. العينلت: جمعت 80 عينة دم لنساء مصابك بداء للسكر النوع الأول (بعمر 30 -40) من مركز الوفاء التخصصي لأمراض للسكري والغدد الصم في مستثفى الموصل العلم (محلظة نينوى / العراق)

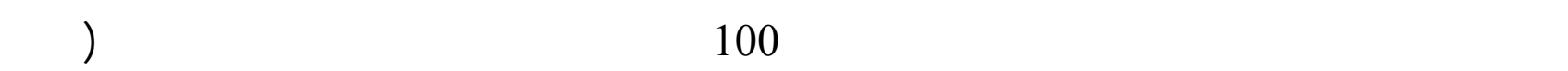

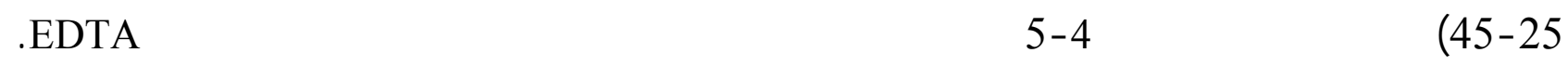
فصلت البلازما بلستخدله جهاز الطرد المركزي المبرد بسرعة (15000g) لمدة (10) دقائق عند درجة المبنة

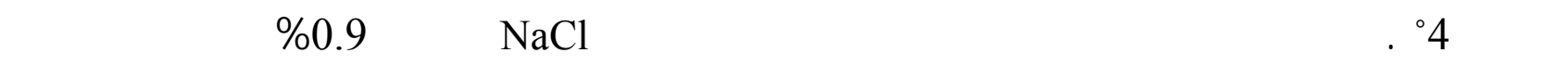

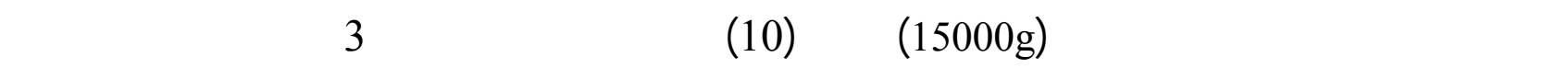
فوصلت بعملية الطرد المركزي المبرد بسرعة (15000g) لمدة (10) دقايق. اعتبر الجزء الرائق متحل

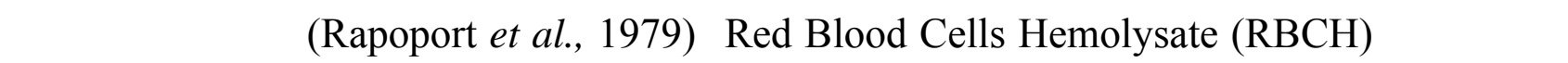

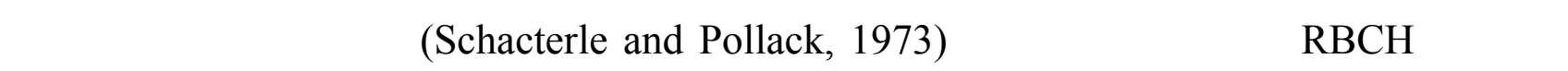

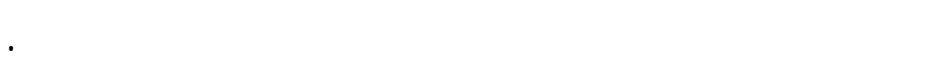

\section{قيلس فعالية إنزم PAOفي البلازما والخلايا الحمر:}

مُ قيلس فعالية أنزيم PAO لعينات البلازما ومتحل الخلايا الحمر في نفس اليوم بإتباع الطريقة

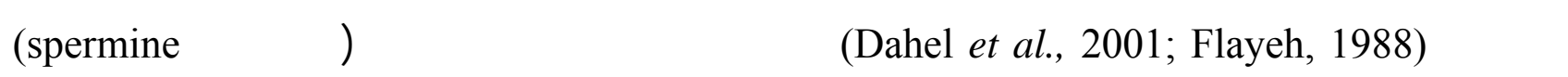
بتركيز 100mM بوسطة أنزيم PAO وبلستخدلم محلول فيريسيانيد البوتلسيوم بتركيز 100mM لذي يعهل مسقبلاً للالكترونات وبوجود الأوكسجين ولستخده المحلول المظم

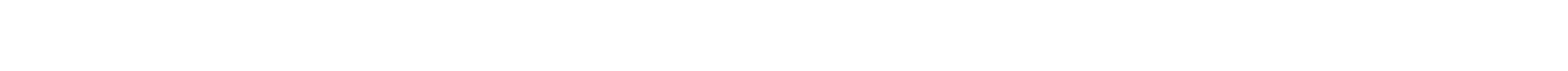

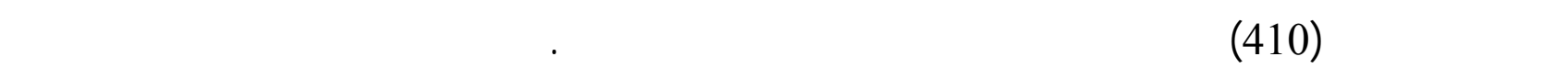

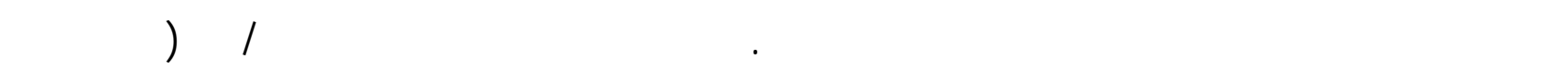
الأنزيم التي تؤهسدمايكرومول ولحد من المادة الأسلس في الدقيقة).

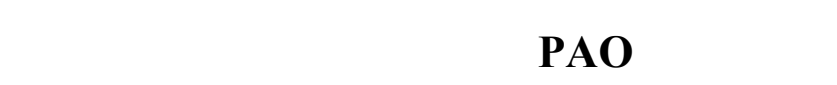
تمت التقية الجزئية لأنزيم PAO الموجود في متحل الخلايا الحمر للمصابلت بداء للسكرمن النوع الأول وللسليملت بعد قيلس الفعالية بالغطوات الآتية:

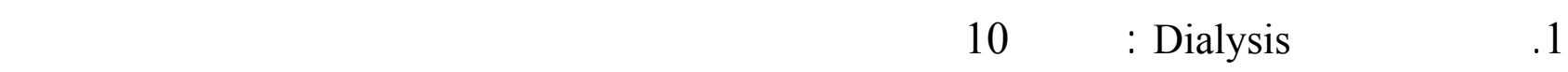
بالجزيئت ذات الأوزان الجزيئية الألف من 10kD بالفاذ من خلاله مقالل الماء المتطر لمدة 6 مساعات 
عند درجة 40م مع التحريك بلستخدلم المحرك المغنلطيسي، قيست فعالية الأنزيم وتركيز البروتين للعينة بعد عملية الفرز الغشائي (Robyte and White, 1987). 2. كروماتوغرافيا التبال الأيوني: لإستخم المبال الأيوني للساب DEAE - سيليلوز اعتمادا على

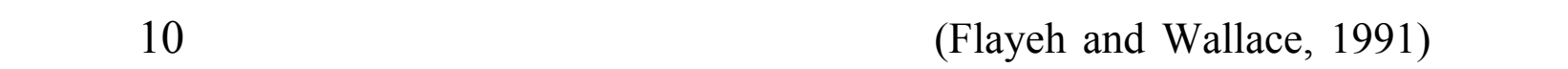
اعلى عمود الفصل المعبأ بال _DEAE-سيليلوز طبول 40سم وتطر 2.5سم، ولستخدم المحلول المظم

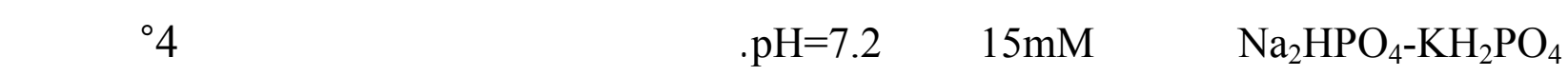
جريان 3. المل / دقيقة (68 مل/ساعة) وجمعت الأجزاء الناتجة من عملية الفصل يدويا ثم قيس تركيز

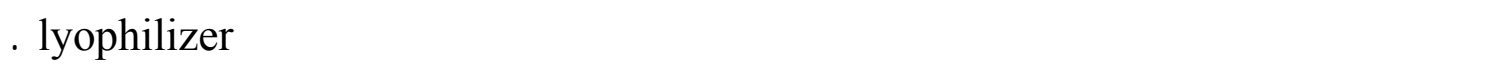

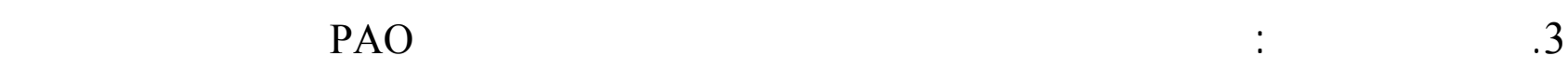

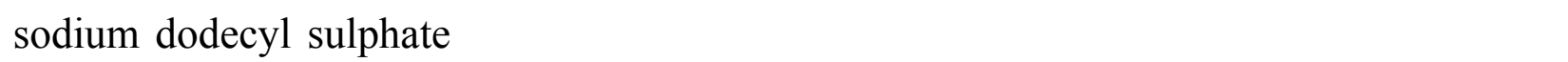
(Robyte and White, 1987) polyacrylamide gel electrophoresis (SDS-PAGE) وزنها الجزيئي بالمقارنة مع مركبلت بروتينية قيلسية ذات أوزان جزيئية معلوم ـة: الي -وريز البومين مصل الأقار 67000، البيروكسيز 40000، التربسين 23800 وللسايتوكروم اوكسيديز 13000 والئين دالتون .

\section{تحضيرمركبك الثاليوبوربا}

حضرت مركبات ثايويوريا بقاعل( 0.01 مول) كلوريد البنزواليل مرة وكلوريد البارا -تولوينسلفونايل

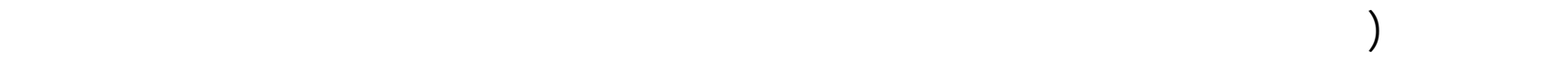

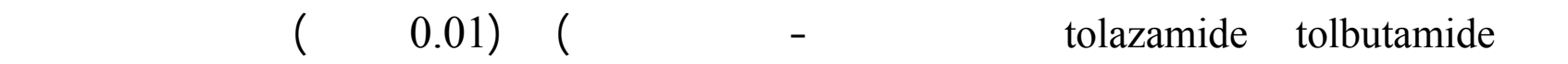

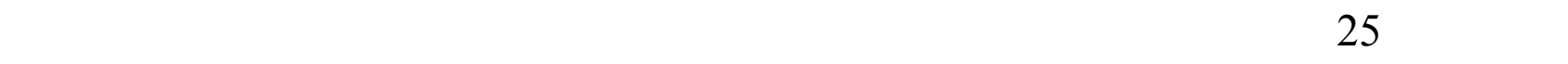

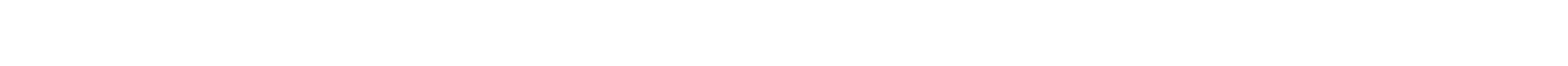

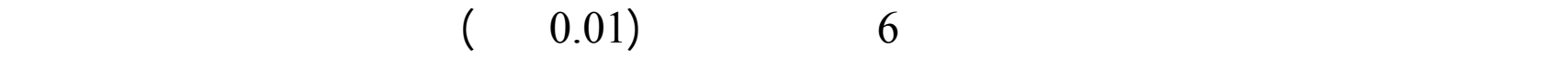

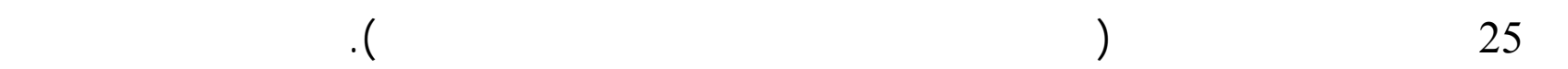

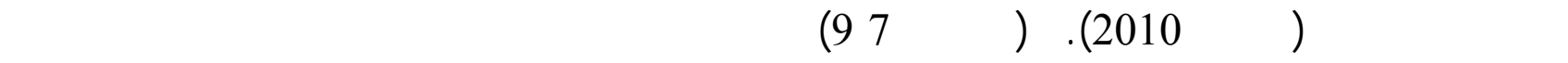
الدقيق للعناصر على التوالي للمركبلت المحضرة. قم التلكدمن قاوة المركبت الناتجة بكروماتوغرافيا الطقة

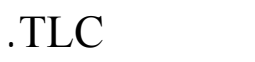

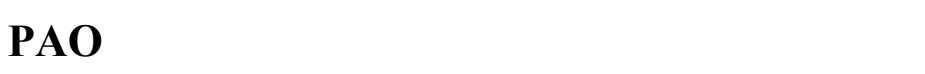

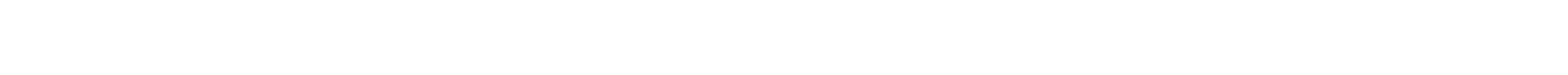

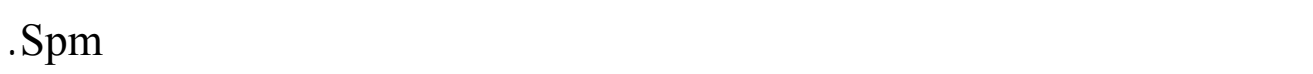




\section{الهثف المرلق الأنزبي المتمائلت PAO المقاةمن خلايا الم الحمر}

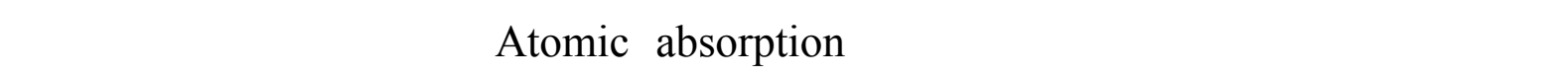
SENSAA-GBC Scintific Equipment

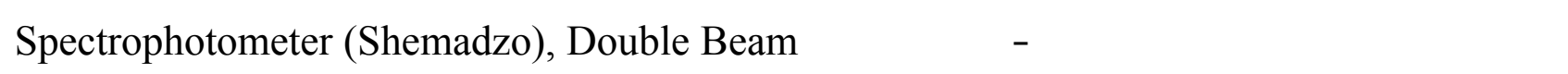

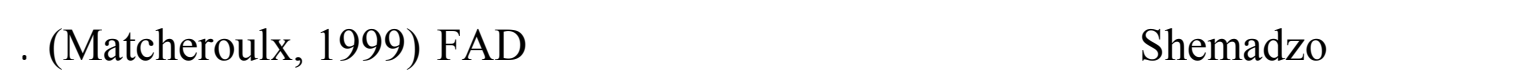

\section{النتائج و المنافشة}

فعالية أنزم بولي أمبن أوكسيديز

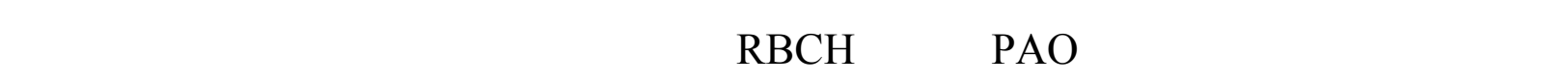

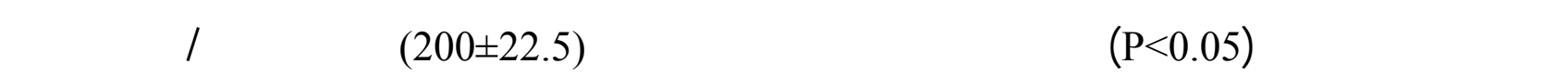

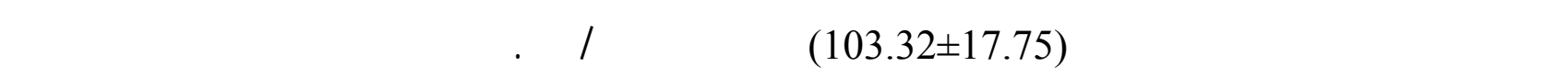

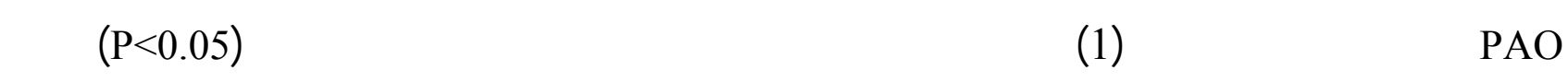

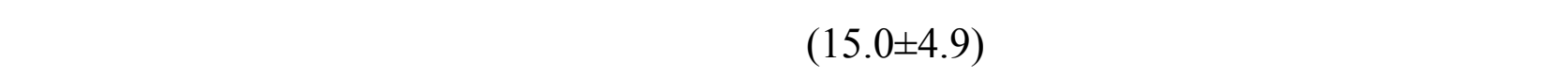

\section{الجطر 1:فعالية أنزيم PAOفي خلايا العم الحمر وملازما الم}

\begin{tabular}{|c|c|c|c|c|}
\hline $\begin{array}{c}\text { Unit/mg protein }\left(\times 10^{2}\right) \\
\text { Mean } \pm \text { SD }\end{array}$ & $\begin{array}{l}\text { البروتين } \\
\text { mg/ml }\end{array}$ & $\begin{array}{c}\text { فعالية أنزج:PAO } \\
\text { Unit/ml (×10²) } \\
\text { Mean } \pm \text { SD } \\
\end{array}$ & \multicolumn{2}{|c|}{ الحالة } \\
\hline $\begin{array}{c}\mathrm{a} \\
3.62 \pm 0.35 \\
\end{array}$ & $\begin{array}{c}\mathrm{a} \\
28.53 \pm 11.85 \\
\end{array}$ & $\begin{array}{c}\mathrm{a} \\
103.32 \pm 17.75 \\
\end{array}$ & للسليملت & \multirow[b]{2}{*}{ خلايا الهم } \\
\hline $\begin{array}{c}\mathrm{c} \\
6.18 \pm 0.55\end{array}$ & $\begin{array}{c}\mathrm{ab} \\
32.13 \pm 3.85\end{array}$ & $\begin{array}{c}c \\
200 \pm 22.5\end{array}$ & مصابت بللسكري & \\
\hline $\begin{array}{c}\mathrm{b} \\
0.128 \pm 0.05\end{array}$ & $\begin{array}{c}\mathrm{a} \\
73.47 \pm 3.57\end{array}$ & $\begin{array}{c}\mathrm{c} \\
6.18 \pm 0.55\end{array}$ & للسليمات & \multirow{2}{*}{ بلازما الدم } \\
\hline $\begin{array}{c}\mathrm{c} \\
0.15 \pm 0.06\end{array}$ & $\begin{array}{c}\mathrm{d} \\
100.39 \pm 3.85\end{array}$ & $\begin{array}{c}\mathrm{b} \\
15.0 \pm 4.9\end{array}$ & مصابت باللسكري & \\
\hline
\end{tabular}

p>0.05 الحروف المختلفة عموياً تشير الى لختلاف معنوي عند مستوى لحتمالية

وقد وجد (العبلي، 2003) زيادة معنوية بمستوى فعالية الأنزيم في للسائ المخي للشوكي للألفل

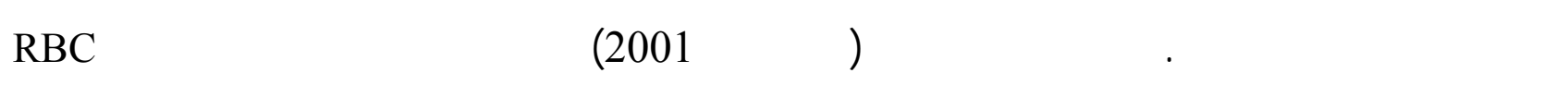

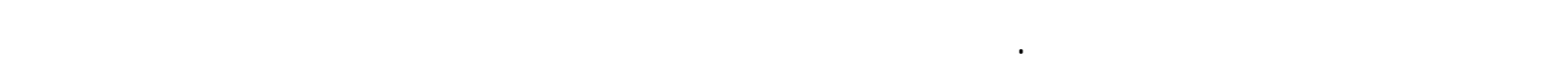


لكبر من تلك الني في البلازما في اللسليمات والمصابت بداء للسكر وهذا يظابق مع النتائج الني حصل عليها (الجبوري، 2001) وهذا يؤكد أن الـ ـ RBC هومركز أيض الـ ـ Cohen et al., 1976) PA).

\section{تقفية أنزم:PAOمن خلايا الم الحمر 1. التقية بوسلة الفرز الغنائي}

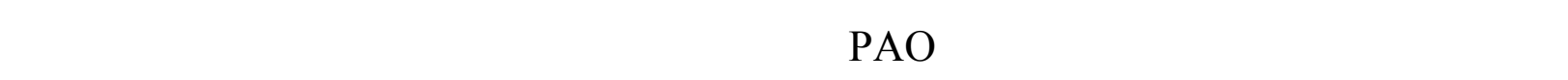

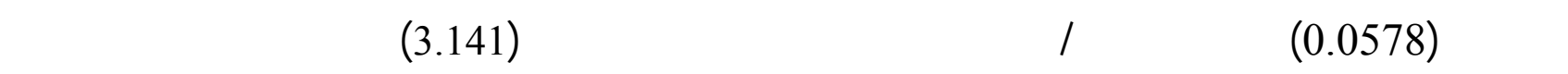

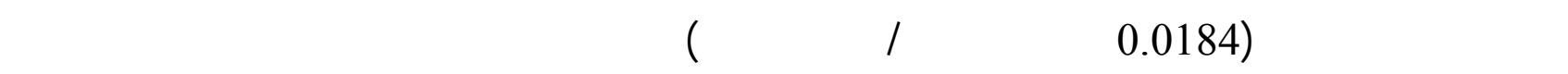

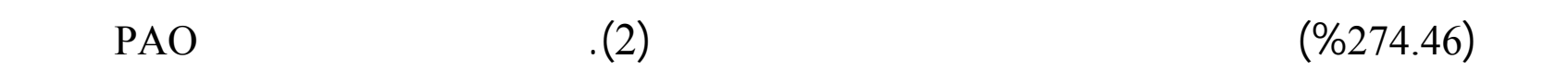

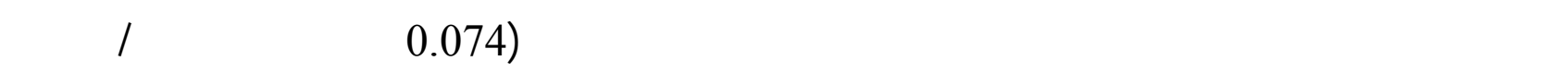

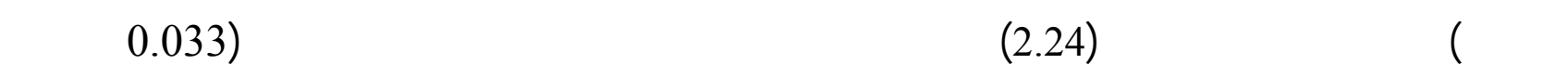

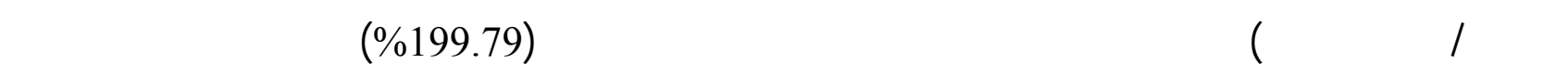

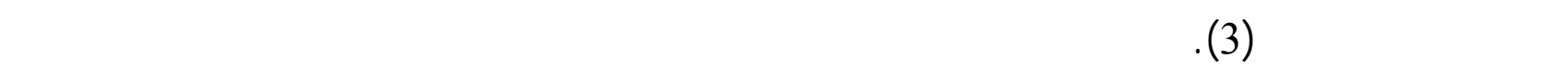

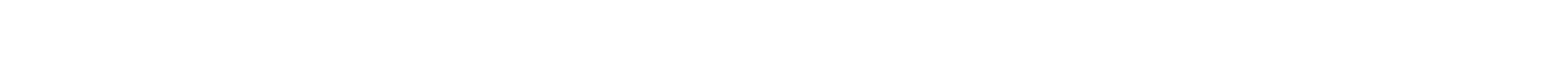
والمثطل(Robyt and White, 1987).

\section{2. التقية بقنية كروماتوغرليا التبال الايوف:}

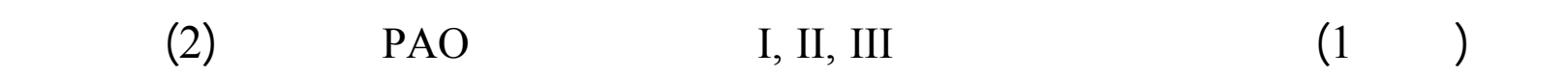

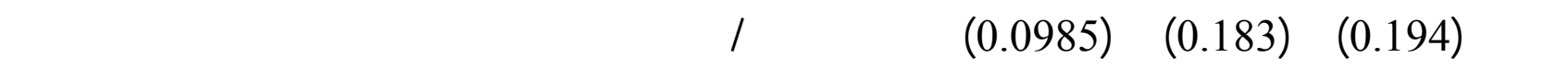

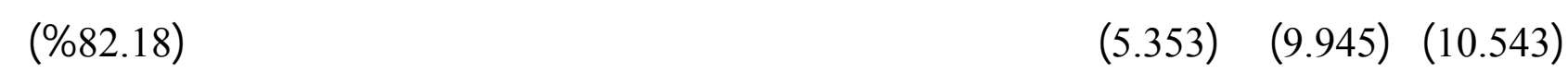
(\%74.13\%) و (10.15.25) (353) على التوالي مقارنة بالفعالية الكلية للأنزيم الخلم.

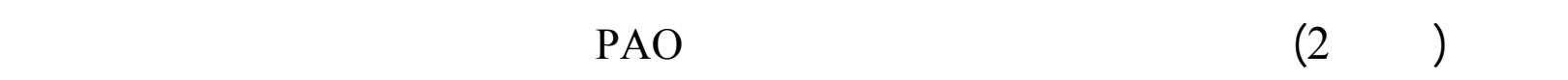

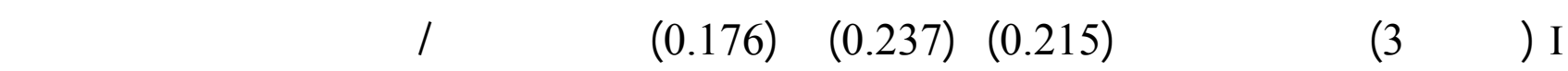

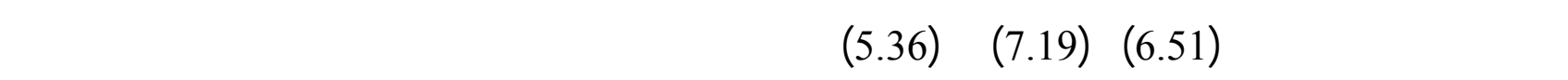

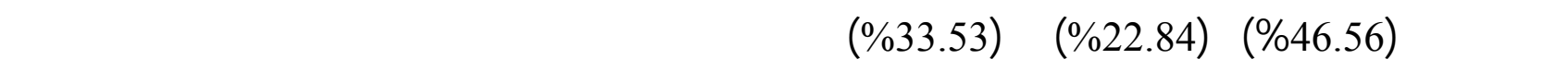

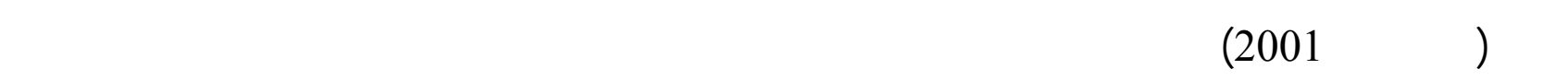
بينما وجدت البلحثة (ميخا، 2002) ثلاث قمم في للسالل المخي الشوكي للأطفل للسليمين والمصابين بالتهاب 


\section{الجطل 2: خطول تقفية أنزم PAOمن خلايا العم الحمر للنساء السليملت}

\begin{tabular}{|c|c|c|c|c|c|c|c|c|}
\hline الالسترجاع & عدممرال & $\begin{array}{c}\text { النهالية } \\
\text { النوعية } \\
\text { Unitl\mg } \\
\text { protein }\end{array}$ & $\begin{array}{c}\text { الهعالية الكلية } \\
\text { Unit/ml }\end{array}$ & $\begin{array}{l}\text { *لdمالية } \\
\text { Unit/ml }\end{array}$ & البلي ملغم & الهلي & \multicolumn{2}{|c|}{ خطولت التقية } \\
\hline 100 & 1 & 0.0184 & 7.95 & 0.795 & 429.75 & 10 & \multicolumn{2}{|c|}{ الأنزم الخلم } \\
\hline 274.46 & 3.141 & 0.0578 & 21.82 & 2.079 & 377.25 & 10.5 & \multicolumn{2}{|c|}{ Dialysis الفرز الغشائي } \\
\hline 82.18 & 10.543 & 0.194 & 6.534 & 0.108 & 33.56 & 60.5 & Peak I & كروماتوغرافيا \\
\hline 74.13 & 9.945 & 0.183 & 5.886 & 0.121 & 32.07 & 48.3 & Peak II & التبلال \\
\hline 35.25 & 5.353 & 0.0985 & 2.803 & 0.081 & 28.45 & 34.5 & Peak III & الايوف DEAE \\
\hline
\end{tabular}

* الوحة الأنزيمية U شتير إلى كمية الأنزيم الني يؤكسد مايكرومولاً ولحداً من المادة الأسلس في الدققة الولحة.

الجطل 3: خطولت تقفية أنزم PAOPن خلايا الم الحمر للنساء المصلبت بالسكر Type-I

\begin{tabular}{|c|c|c|c|c|c|c|c|c|}
\hline اللسترجاع العالية & مرل & $\begin{array}{l}\text { الفعالية النوعية } \\
\text { Unitllmg } \\
\text { protein }\end{array}$ & الفعالية الكلية & $\begin{array}{l}\text { * الdطالية } \\
\text { Unit } / \mathrm{ml}\end{array}$ & البلي ملنم & الهلي & \multicolumn{2}{|c|}{ خلولت التقية } \\
\hline 100 & 1 & 0.033 & 24.16 & 2.416 & 714.75 & 10 & \multicolumn{2}{|c|}{ الأنزمج الخلم } \\
\hline 199.79 & 2.24 & 0.074 & 48.27 & 4.687 & 651.21 & 10.3 & \multicolumn{2}{|c|}{ Dialysis الفرز الغشائي } \\
\hline 46.56 & 6.51 & 0.215 & 11.25 & 0.206 & 52.17 & 54.5 & Peak I & كرومالتوغرليا \\
\hline 22.84 & 7.19 & 0.237 & 5.52 & 0.203 & 23.249 & 27.2 & Peak II & التبال \\
\hline 33.53 & 5.36 & 0.176 & 8.103 & 0.108 & 45.8 & 74.8 & Peak III & الايوف سسليولوز \\
\hline
\end{tabular}

* الوحة الأنزيمية U شتير إلى كمية الأنزم الذي يؤكسدمايكرومولاً ولحدأمن الماة الأسلس في الدقةة الولحة. 


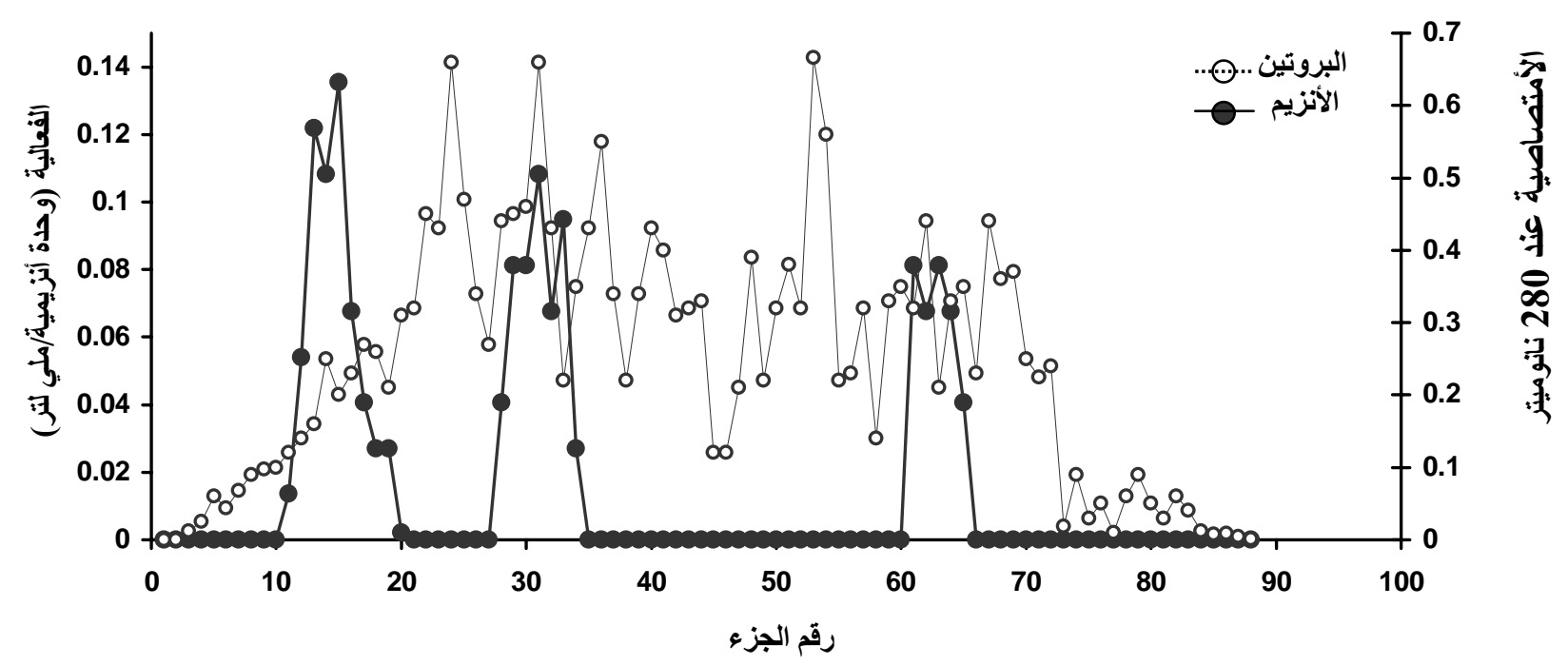

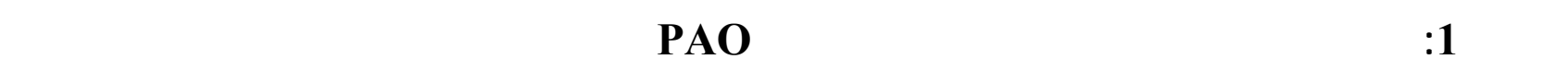

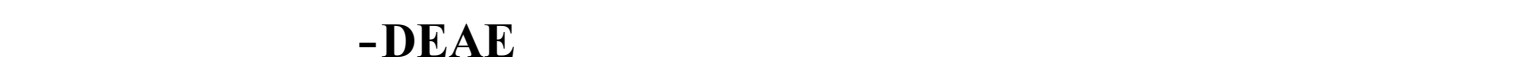

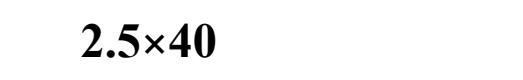

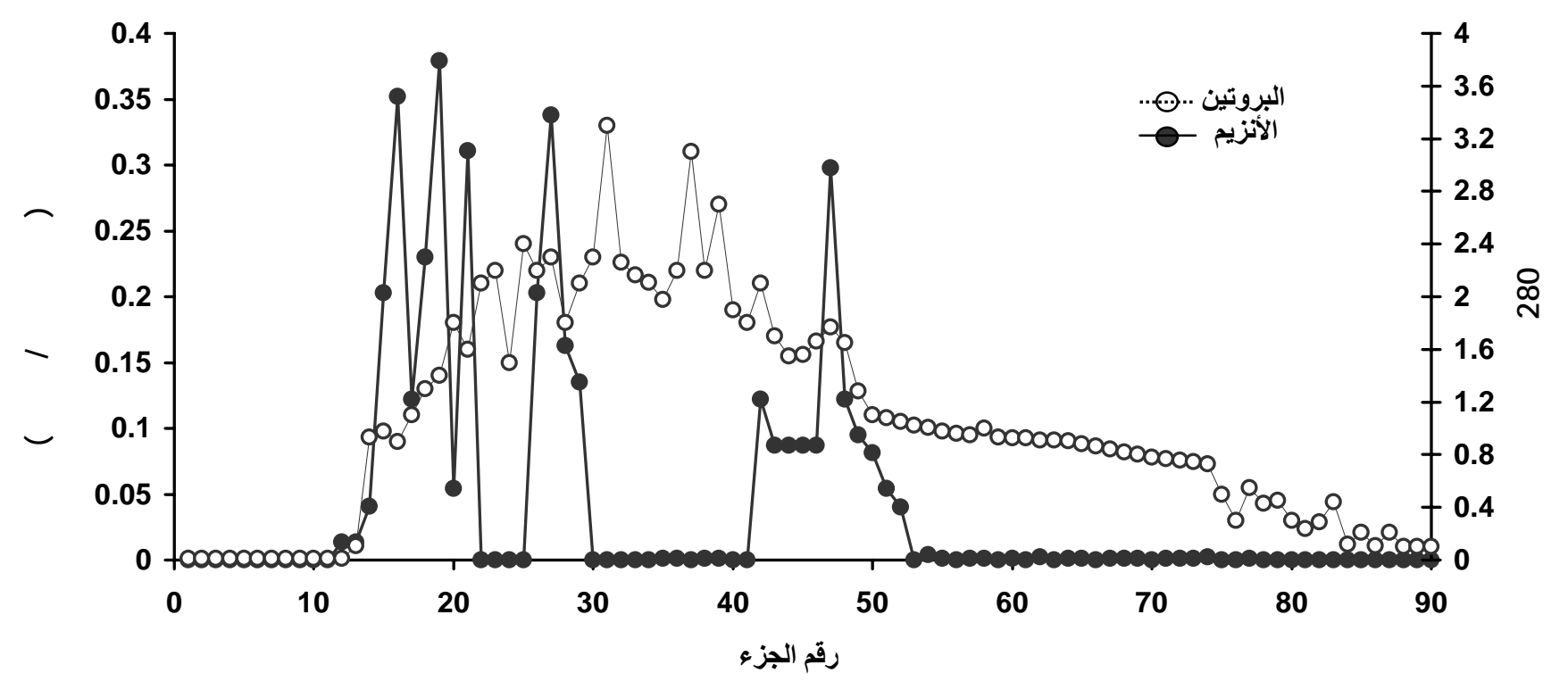

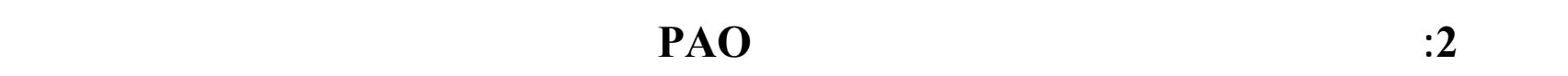

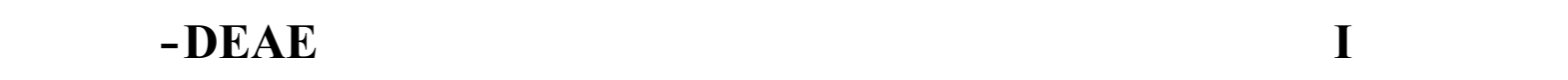
المعبأ بمود الفمل نى الأبعاد 


\section{وجود ونوع المرائ الأنزبي}

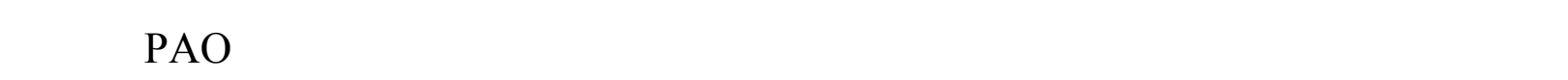

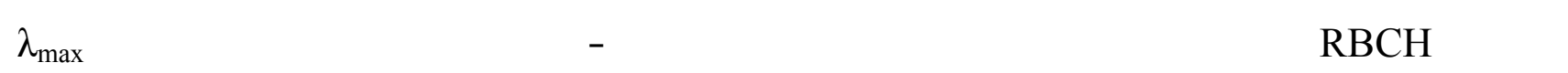

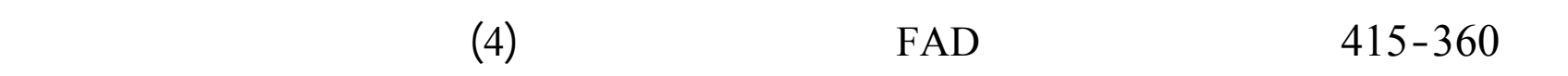
أنزيم مونو أمين أوكسيديز Monoamine Oxidase يكون مررافقه ايون النحلس (

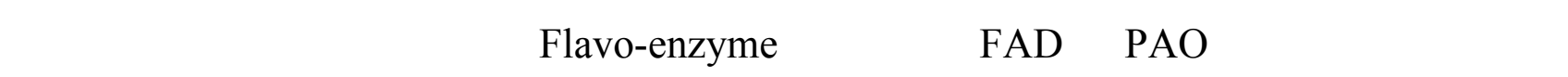
والانسجة الحيوانية (Cona, 2006) ويبديلن حزم المتصاص مميزة عند الطول الموجي المق ارب 360 -450 دلالة على وجود ال ـ Matcheroulx, 1999) FAD).

\begin{tabular}{|c|c|c|c|c|}
\hline \multicolumn{2}{|c|}{ 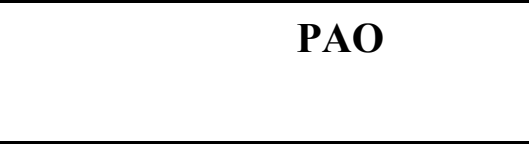 } & \multicolumn{2}{|c|}{ متمال PAO المق Pن م } & \multirow[t]{2}{*}{ تمال لألنزيم } \\
\hline$\lambda \max$ & الامتصاصية & $\lambda \max$ & الامتصاصية & \\
\hline 434 & 0.548 & 426 & 0.063 & Peak I \\
\hline 354 & 0.059 & 367 & 0.035 & \\
\hline 414 & 0.844 & 447 & 0.759 & PeakII \\
\hline 307 & 0.11 & 310 & 0.557 & \\
\hline 414 & 0.353 & 436 & 0.394 & peakIII \\
\hline 361 & 0.032 & 367 & 0.366 & \\
\hline
\end{tabular}

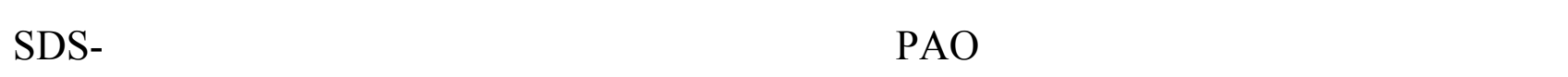
1PAGE، من هم النساء للسليملت والمصابلت بللسكري نوع I من لسم المنحني بين لوغاريم الوزن الجزيئي

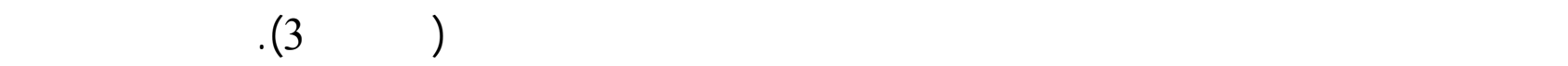

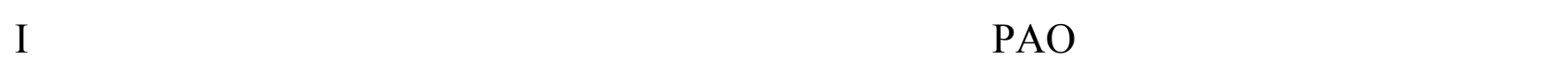
الجدول(5) - الجاوزي

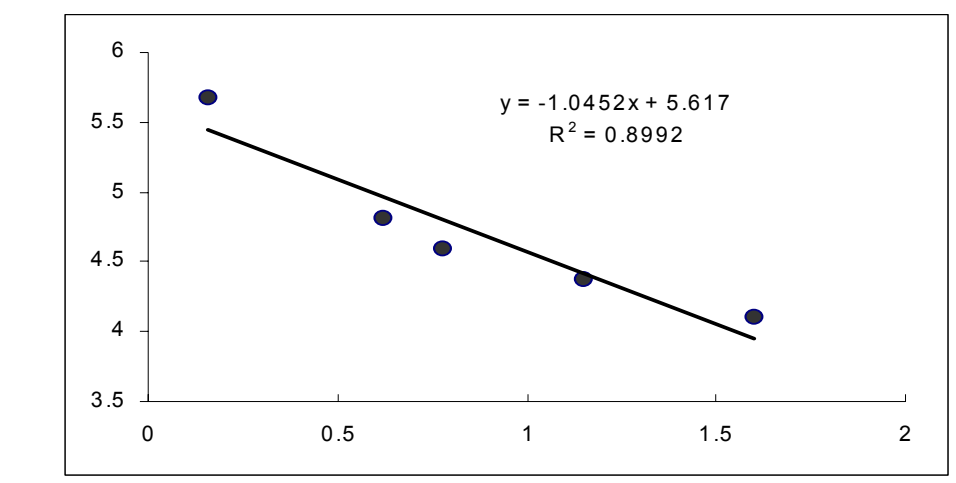

الشكل 3: المنحن الفيلسي لقنير الوزن الجزبئي المتماثلات ألنزم PAO الوزيئي 


\section{الجطر 5: الأوزل الجزبئية المتماثلات أنزجم PAO}

\begin{tabular}{|c|c|c|}
\hline الون الجزيئي & المتمال & الحالة \\
\hline 74512 & Peak I & \multirow{3}{*}{ أنزيم PAO المقى من هم النساء للسليمل } \\
\hline 72588 & Peak II & \\
\hline 69339 & peakIII & \\
\hline 100671 & Peak I & \multirow{3}{*}{ بأنزيم PAO المقى من هم النساء الم ـصابت } \\
\hline 141458 & Peak II & \\
\hline 104018 & peakIII & \\
\hline
\end{tabular}

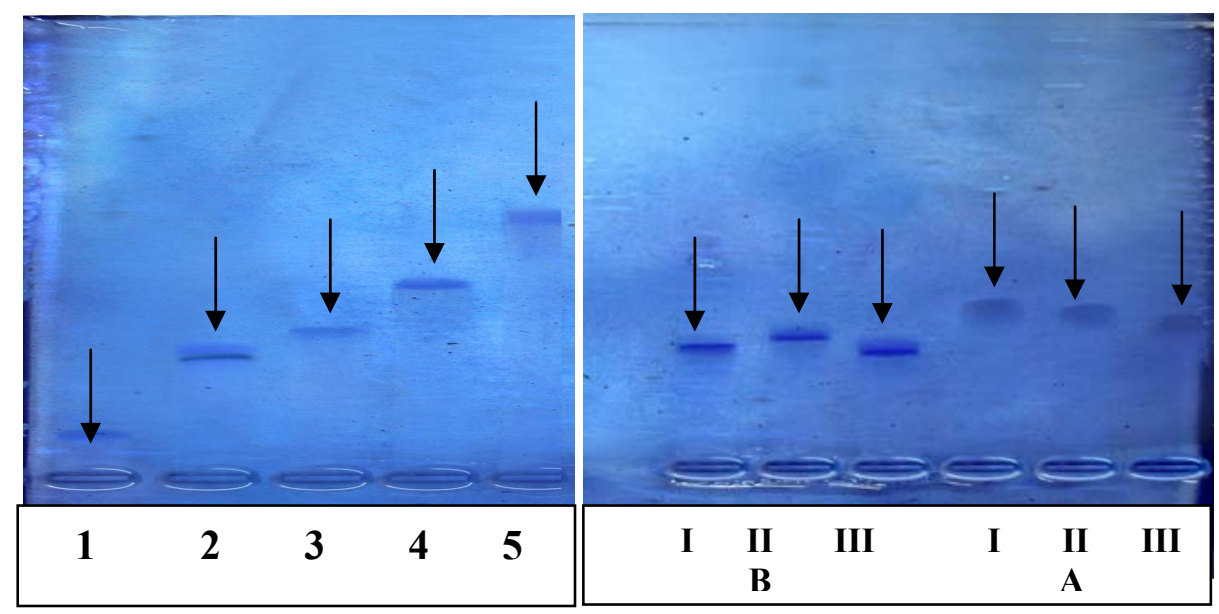

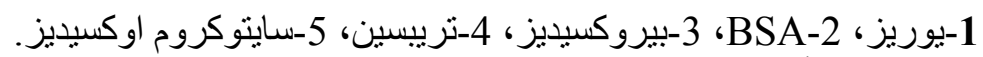

A متماثلات أنزيم PAO المنقاة من دم النساء السليمات.

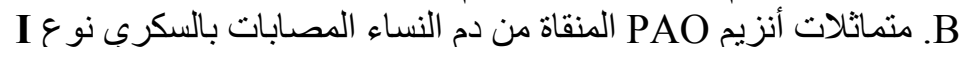

\section{الصورة 1: الهجرة الكهريائية بلستخدلم لمتماثلات ألنزم PAOمع البروتينك الفيلسية}

تأثير مركب الثاليوسيميكاربازبد عل فعالية متماثلات

درس تأثير مركب ثايوسيميكاربازيد على فعالية أنزيم PAO المقى ذي الفعالية النوعية الأعلى ووجد

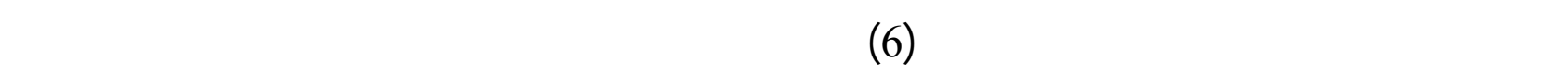

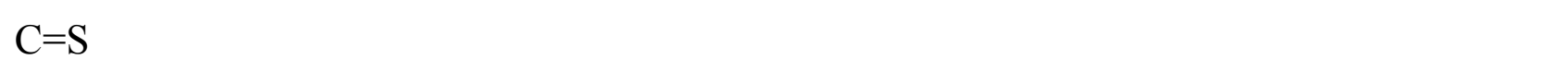

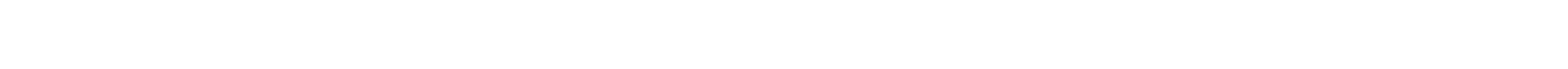
اللسيميكاربازيد (Jalkanen and Salmi, 2001) إذ أن لهذه المجموعة قابلية للتدلخل مع الموقع الفعل للأنزيم وبالتالي تعل على تثبيط الفعالية الأنزيمية لأنزيم PAO. 


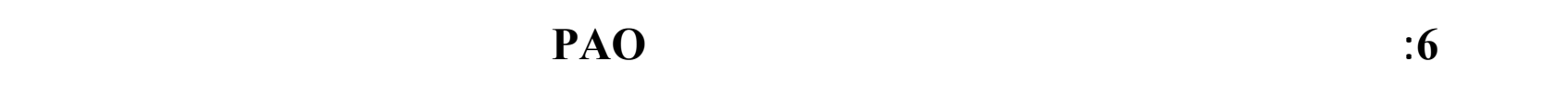

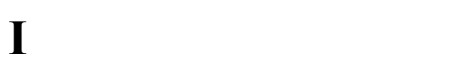

\begin{tabular}{|c|c|c|c|c|}
\hline \multicolumn{2}{|c|}{ 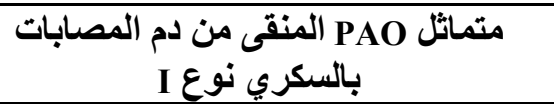 } & \multicolumn{2}{|c|}{ متماثل PAO المنقى من دم السليمات } & \multirow[b]{2}{*}{$\begin{array}{c}\text { (ملي مولار) } \\
\end{array}$} \\
\hline اللنببة المئوية & 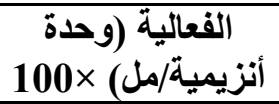 & اللنببة المئوية & 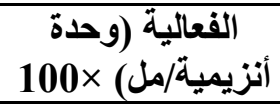 & \\
\hline$\%$ & 13.54 & $\%$ & 10.8 & سيطرة بدون مثبط \\
\hline 10 & 12.18 & 0 & 10.8 & 25 \\
\hline 10 & 12.18 & 0 & 10.8 & 50 \\
\hline 50 & 6.77 & 12.5 & 9.47 & 75 \\
\hline 60 & 5.41 & 50 & 5.41 & 100 \\
\hline 60 & 5.41 & 37.5 & 6.77 & 125 \\
\hline 50 & 6.77 & 37.5 & 6.77 & 150 \\
\hline 50 & 6.77 & 37.5 & 6.77 & 175 \\
\hline
\end{tabular}

حضر مشنقي الثايويوريا (A و B A) من تقاعل مركبي كلوريد البززواليل وكلوريد البارا-تولوين سلفونالي مع ثايوسيانات البوتلسيوه ومن مُ مفاعلة المركبلت الوسطية الناتجة مع الثايوسيميكاربازيد.<smiles>NC(=S)NNC(=S)NC(=O)c1ccccc1</smiles>

1-(benzamido thiocarbonyl) thiosemicarbazide (A)<smiles>Cc1ccc(S(=O)(=O)NC(=S)NNC(N)=S)cc1</smiles>

1-(p-toluene sulfonamido thiocarbonyl) thiosemicarbazide (B)

الجطر 7: الخواd الفيزباوبة لمركبلت الثليوبوربا المحضرة

\begin{tabular}{|c|c|c|c|c|c|}
\hline Compound & $\begin{array}{c}\text { Molecular } \\
\text { formela }\end{array}$ & $\begin{array}{c}\text { m.p } \\
{ }^{\circ} \mathbf{C}\end{array}$ & $\begin{array}{c}\text { Yield } \\
\text { \%o }\end{array}$ & Color & Rf \\
\hline A & $\left(\mathrm{C}_{9} \mathrm{~N}_{4} \mathrm{~S}_{2} \mathrm{OH}_{10}\right)$ & 140 & 45.49 & yellow & 0.822 \\
\hline $\mathrm{B}$ & $\left(\mathrm{C}_{9} \mathrm{~N}_{4} \mathrm{~S}_{3} \mathrm{O}_{2} \mathrm{H}_{12}\right)$ & 96 & 51.33 & Brown & 0.866 \\
\hline
\end{tabular}

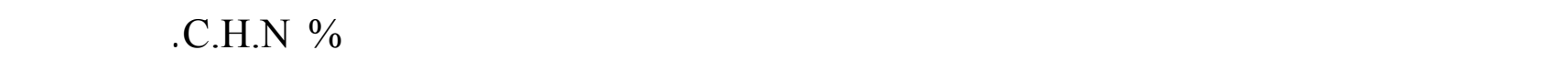
طيف الاشعة تهت الحمراء(للشكلين 4،5) حزم المتصاص عند الترددات 3160-3377سمة -1269 و و 1246 1269 1سم - تعود لمط اواصر N-H و C=S على التوالمي، فضلا عن ذلك ظظهر المركب A حزمة حادة عند 
التردد 683 السم -1 تعود لط الصرة C=O الميدية، بينما لظهر طف المركب B حزمتي لمتصاص عند

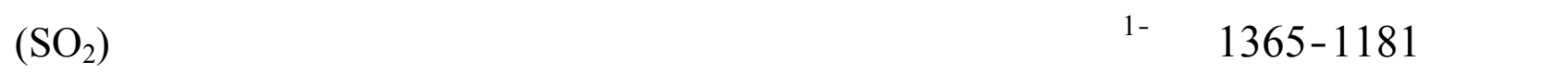

الجدول(8) (1) (1)

الجطل 8: أهم ترددل المتصلص لامركبين A وB للاف الثعة تهت الحمراء

\begin{tabular}{|c|c|c|c|c|c|c|c|}
\hline \multirow{2}{*}{ Compound } & $\begin{array}{c}\mathrm{C}-\mathrm{H} \\
\text { aliphatic }\end{array}$ & $\begin{array}{c}\mathrm{C}=\mathrm{C} \\
\text { aromatic }\end{array}$ & $\begin{array}{c}\mathrm{C}=\mathrm{S} \\
\text { Stretch }\end{array}$ & $\begin{array}{c}\mathrm{O} \\
-\mathrm{C}-\mathrm{NH}- \\
\text { Amid }\end{array}$ & $\begin{array}{c}\mathrm{C}-\mathrm{H} \\
\text { Bending }\end{array}$ & $\begin{array}{c}\mathrm{S}=\mathrm{O} \\
\mathbf{a s y m} \\
\text { sym }\end{array}$ & $\begin{array}{c}\mathrm{N}-\mathrm{H} \\
\text { Stretch }\end{array}$ \\
\hline $\mathrm{A}$ & -- & $\begin{array}{c}1599, \\
1560\end{array}$ & 1246 & 1683 & 763 & -- & 3371, \\
$\mathrm{~B}$ & 2997 & $\begin{array}{c}1596, \\
1512\end{array}$ & 1269 & -- & 804 & 1365, & 3377, \\
& & & & & 1181 & 3233, \\
\hline
\end{tabular}

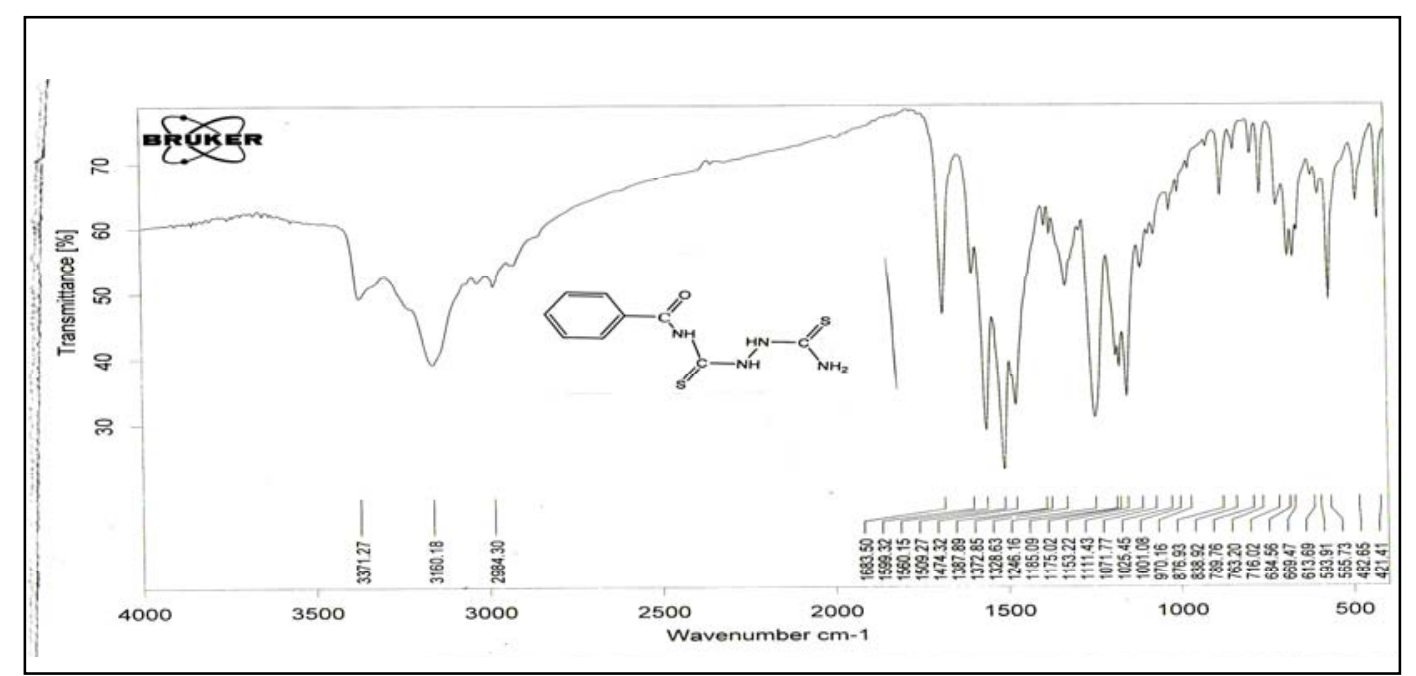

الشكل 4:طلف الأشمة تحت الحمراء لامركب A

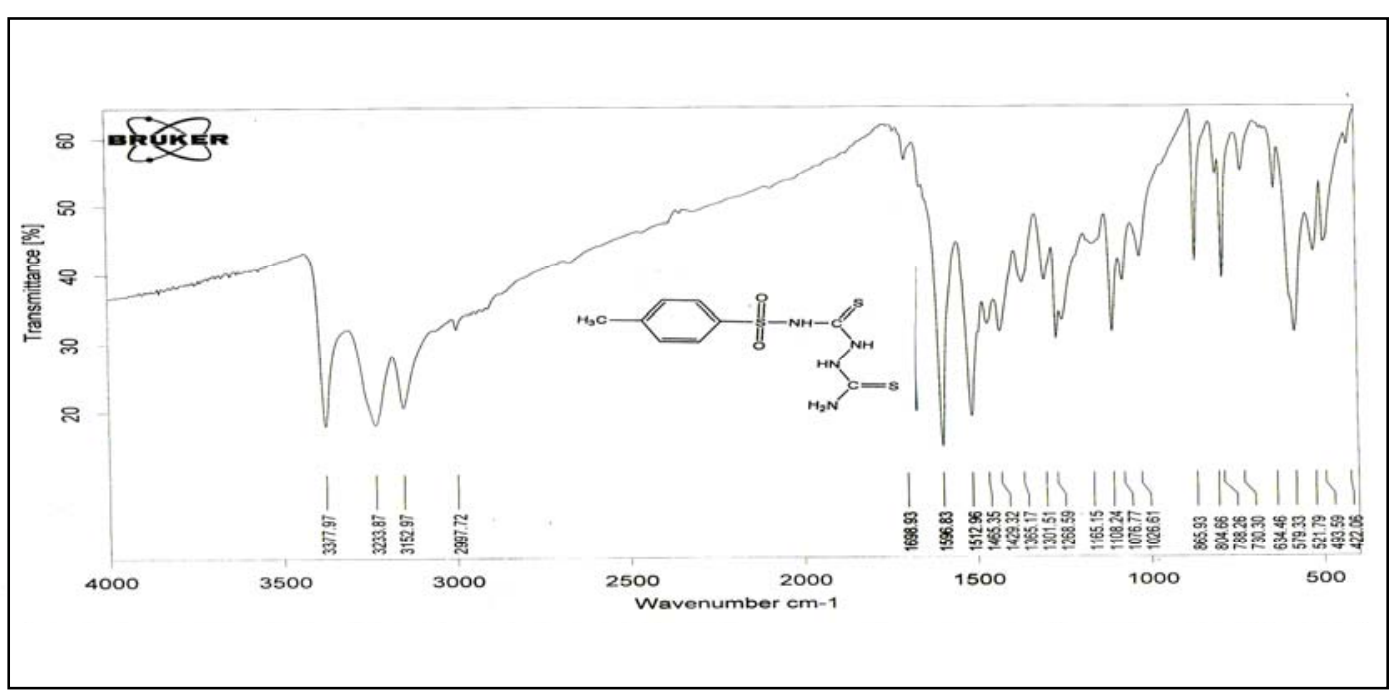

الثكل 5: طيف الاشعة تحت الحمراء للمركب B 
لظهرطف م HNMR 10 ppm (للشكل 6) للمركب A الازلحك الكيمياوية الاتية : لشارة لحاية عند

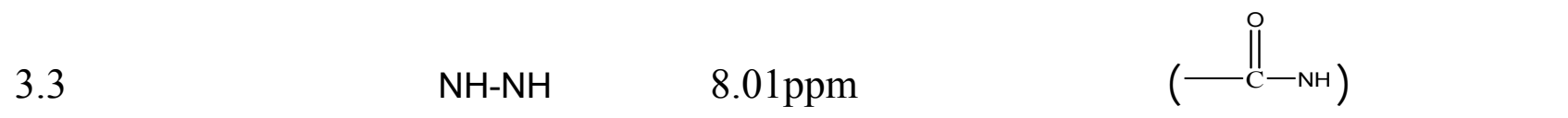

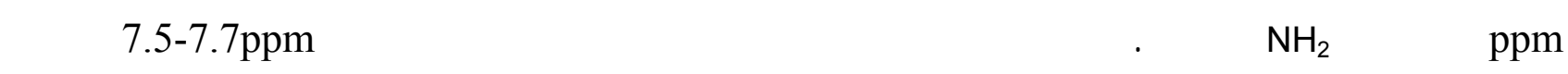

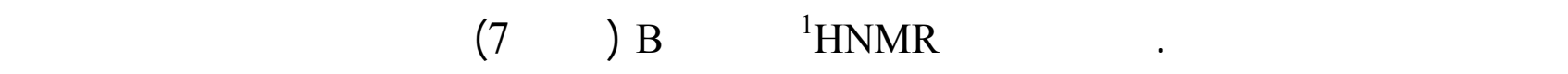

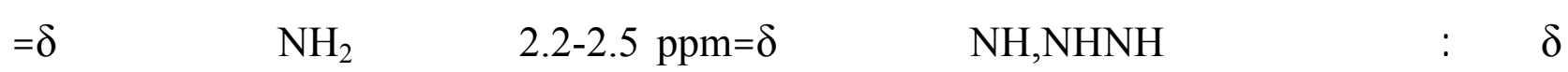
3.34 ppm .4H , phenyl _ J 7.9 ppm

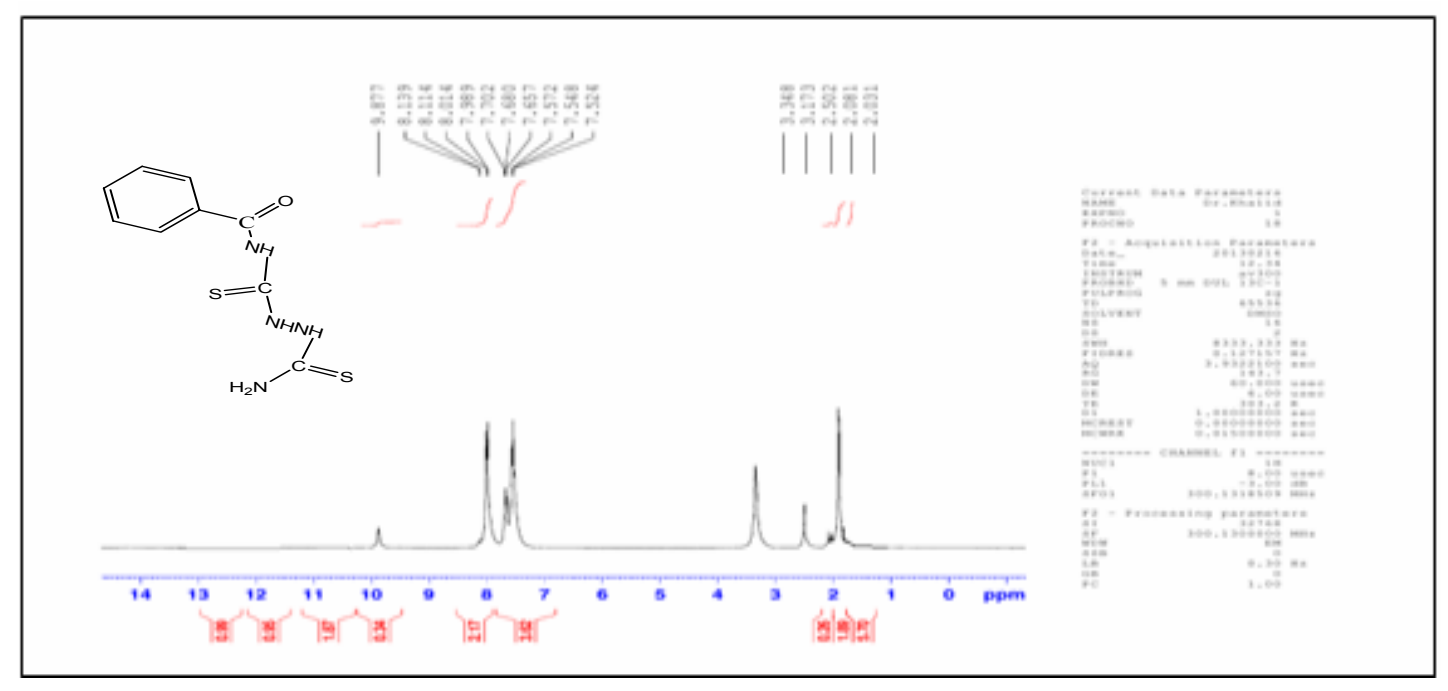

الشكل 6:طلف الرنين النووي المغنليس H NMR لالمركب

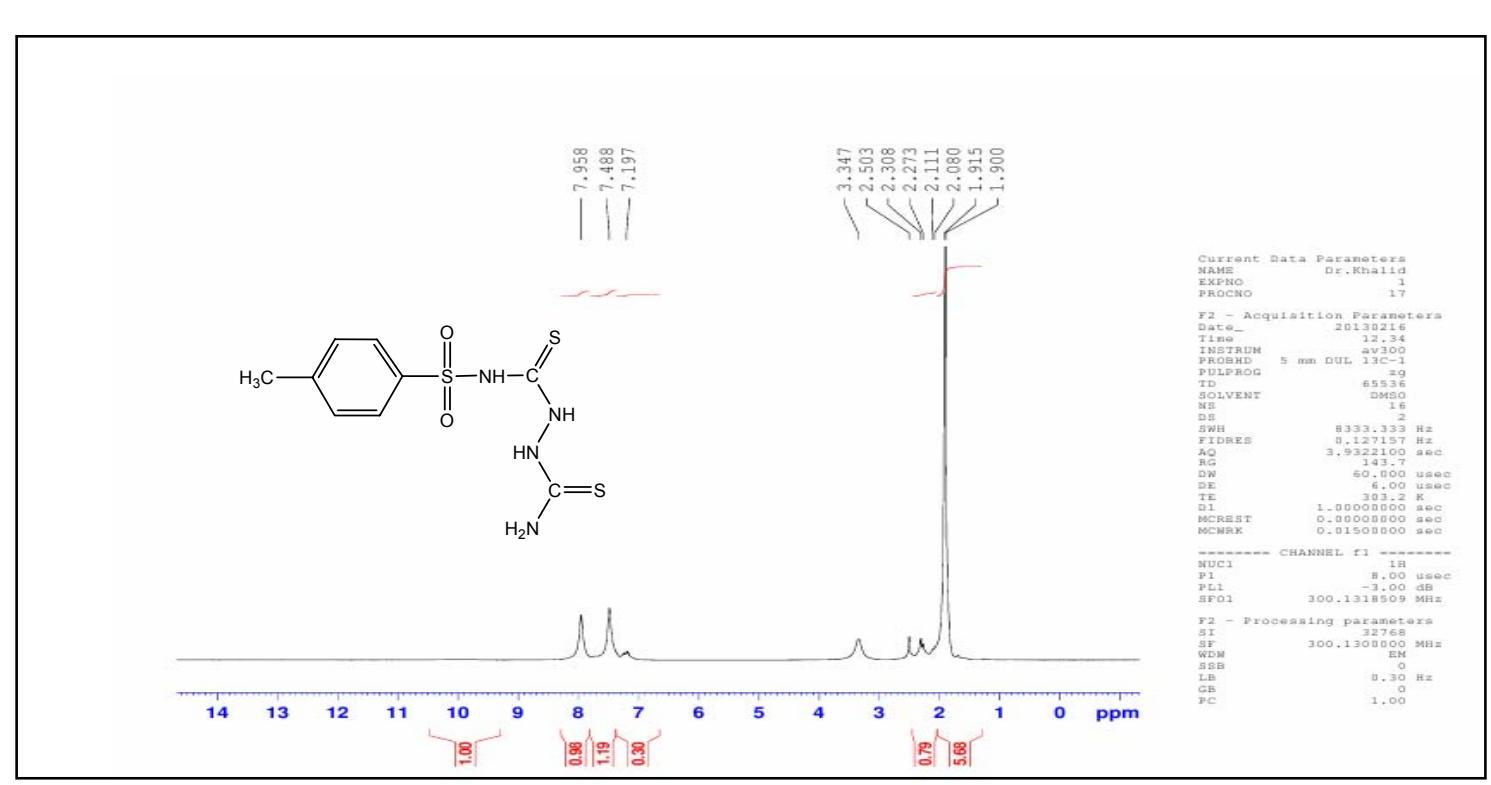


شخصت المركبت المحضرة اليضا من خلل التحليل العنصري الدقيق للعناصر(CHN) وقد لظهرت A القيلست الموضحة في الجدول (9) قيمامقابقة تقريباً مع القيم الممسوبة وهذا يدل على صحة المركبين

C.H.Nقالجط 9: النسبة المئوبة للزرال بقنية التحلل الهنصري القبق

\begin{tabular}{|c|c|c|c|c|c|c|c|c|}
\hline \multicolumn{9}{|c|}{$\begin{array}{l}\text { C.H.N } \% \\
\end{array}$} \\
\hline \multicolumn{2}{|c|}{$\mathrm{C} \%$} & \multicolumn{2}{|c|}{ H\% } & \multicolumn{2}{|c|}{ N\% } & \multicolumn{2}{|c|}{ S\% } & المركب \\
\hline ظري & عملي & ظري & عملي & ظري & عملي & ظري & عملي & A \\
\hline 42.51 & 42.58 & 3.93 & 5.47 & 22.04 & 22.35 & 25.19 & 25.69 & $n$ \\
\hline ظري & عملي & ظري & عملي & ظري & عملي & ظري & عملي & $B$ \\
\hline 35.52 & 35.78 & 3.94 & 3.46 & 18.42 & 18.49 & 31.57 & 31.85 & \\
\hline
\end{tabular}

كما دسس التأثير التبيطي للمركبين A و B على فعالية النزيم PAO ذي الفعالية الأعلى والمقى من كل

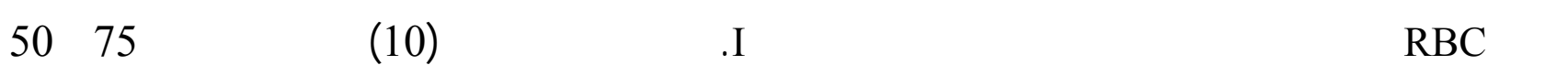
للمركب A و التركيزين 125و100 ملي مولار للمركب B كانت التركيز المثلى لتبيط فعالية الأنزيم

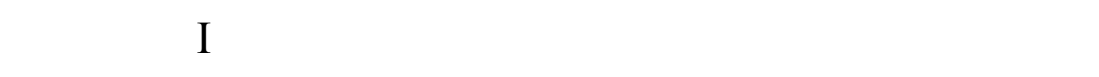

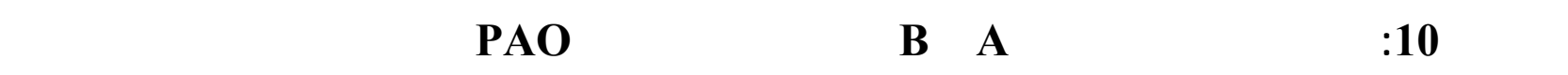
والمصلبلت بالسكري نو لامبرن

\begin{tabular}{|c|c|c|c|c|c|c|c|c|}
\hline \multicolumn{4}{|c|}{ المركب B } & \multicolumn{4}{|c|}{ A المركب } & \\
\hline \multicolumn{2}{|c|}{ 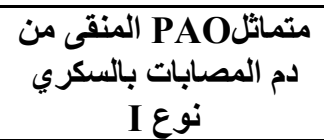 } & \multicolumn{2}{|c|}{ متماثلدAO المنقى من } & \multicolumn{2}{|c|}{ 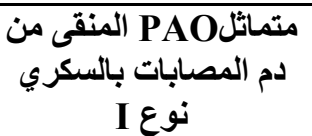 } & \multicolumn{2}{|c|}{ متماثلPAO المنقى من دم } & \\
\hline $\begin{array}{l}\text { اللتبئوية } \\
\text { التبيطبة }\end{array}$ & أنزيمالية وحلة الفية & $\begin{array}{l}\text { اللتئوية } \\
\text { النبيطة\% }\end{array}$ & 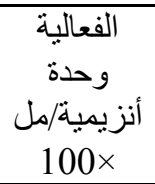 & $\begin{array}{l}\text { اللتبئوية } \\
\text { النبية }\end{array}$ & 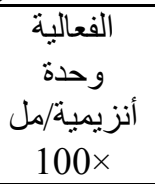 & $\begin{array}{l}\text { النئسبة } \\
\text { اللتبيطبة \% }\end{array}$ & $\begin{array}{c}\text { أنزيمية/ملة } 100 \text { الفعلة } 100 \\
\text { الفية }\end{array}$ & التركيز ملي مو لار \\
\hline$\%$ & 12.18 & $\%$ & 13.54 & $\%$ & 13.54 & $\%$ & 10.83 & سيطرة بدون مثبط \\
\hline 22.2 & 9.47 & 40 & 8.12 & 40 & 8.12 & 37.5 & 6.77 & 25 \\
\hline 22.2 & 9.47 & 20 & 10.83 & 60 & 5.41 & 37.5 & 6.77 & 50 \\
\hline 11.1 & 13.54 & 10 & 12.18 & 50 & 6.77 & 50 & 5.41 & 75 \\
\hline 55.5 & 5.41 & 40 & 8.12 & 40 & 8.12 & 37.5 & 6.77 & 100 \\
\hline 55.5 & 5.41 & 50 & 6.77 & 40 & 8.12 & 37.5 & 6.77 & 125 \\
\hline 44.4 & 6.77 & 40 & 8.12 & 60 & 5.41 & 37.5 & 6.77 & 150 \\
\hline 22.2 & 9.47 & 30 & 9.47 & 30 & 9.47 & 25 & 8.12 & 175 \\
\hline
\end{tabular}


يمكن ان يعزى سبب التبيط هذا إلى توسبع الهيكل الجزيئي وزياة عدد المجلمبع الفعالة الذي مكنت

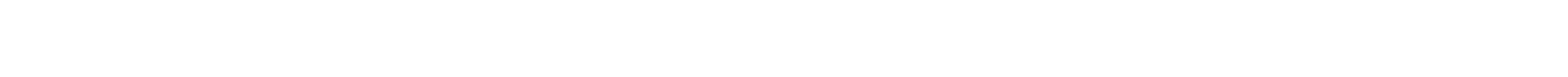
للبنزويل إضلفة إلى مجموعة الثايون C=S التي لها صفة تشبطية مشابهة لمركب اللسيميكاربازيد ( بقت بشكلها الفعل بعد تحضير مشق الثايويوريا. وعند درلسة نوع التبط لأنزيم PAO بهذه المركبات بلستخدلم التركيز الأمل الجدول(8) وجد الهه من النوع التنافسي هسب لسم لينوفر -بيرك كما موضنح في الأشكل الآتية:

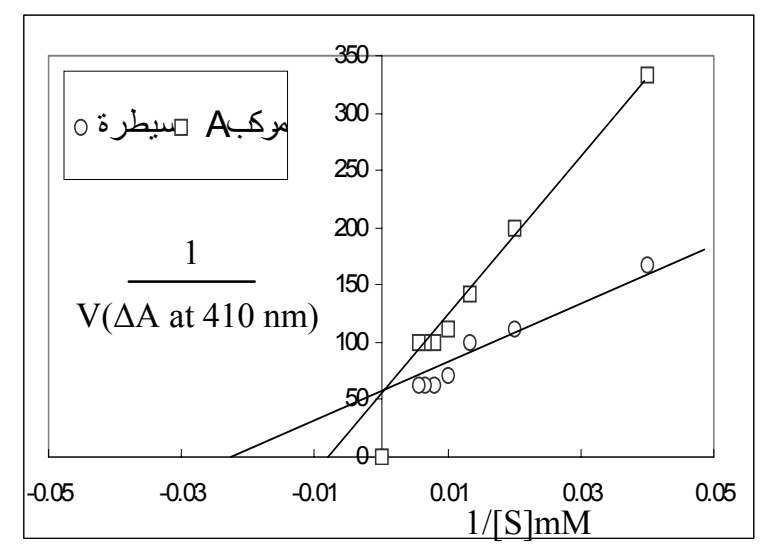

الثلى 8: نوع تنبيا لنزم PAO المق من م النساء اللسليملت

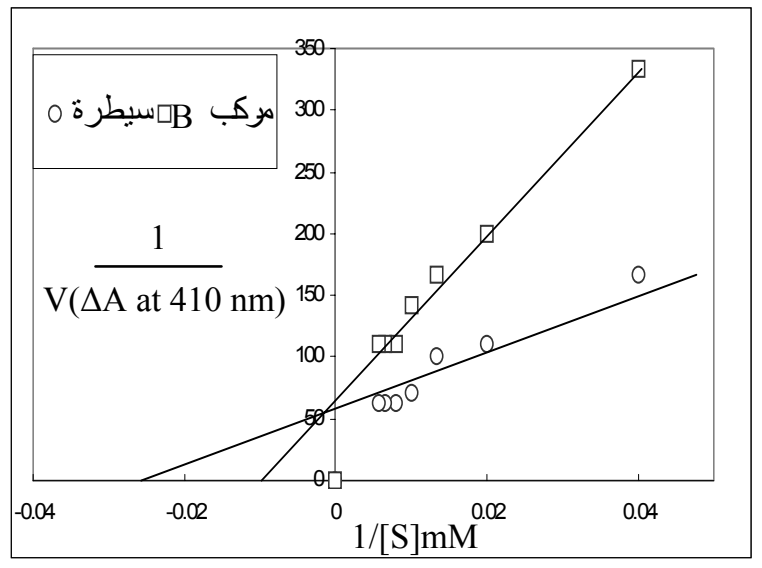

الثل 10: نوع تشبيا أنزم PAO المق من م B النساء اللسليملت بالمركب

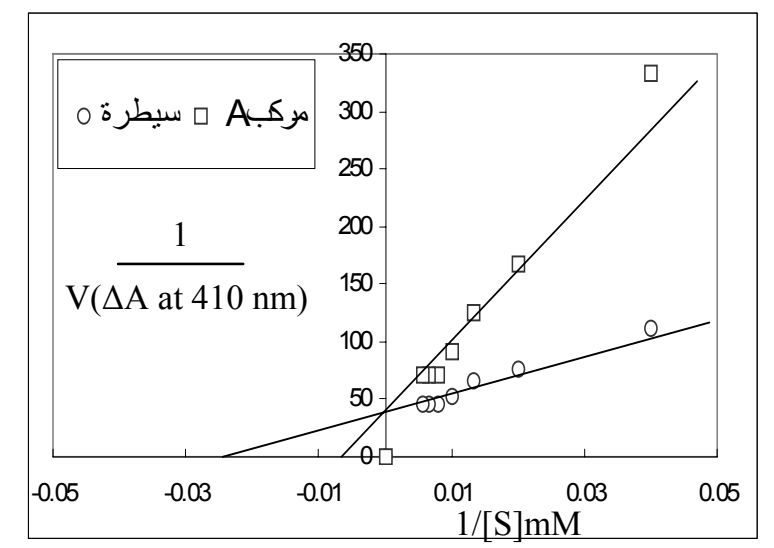

الثكل 9: نوع تشبيا أنزم PAO المق من م النساء المصلبلت

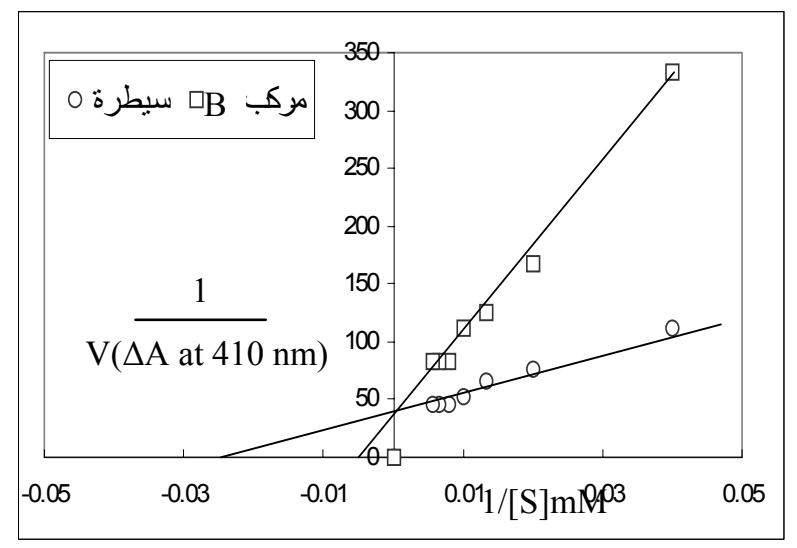

الشكل 11: نوع تنبيا لنزم PAO المقفمن م النساء المصلبلت بالسكري I بالمركب المبع 


\section{الجطل 11: نوع التثبط لأنزم PAO المق من ثم النساء للسليملت والمصلبلت بلالسكري نوع I بوجود وعثم وجودمركبي الثليوبوربا B A المحضرة}

\begin{tabular}{|c|c|c|c|c|c|c|}
\hline نوع التبيطا & $(\mathbf{m M}) \mathbf{K i}$ & $\begin{array}{c}\text { V'max } \\
\text { PAO بوجوالية المثبا } \\
\text { (unit/ml) }\end{array}$ & $\begin{array}{c}\text { بهالية } \\
\text { PAO Vmax } \\
\text { (unit/ml) } \\
\text { بون المبطا }\end{array}$ & $\begin{array}{c}\text { K'm } \\
\text { (mM) } \\
\text { بوجود المبة } \\
\text { PAO } \\
\text { الية }\end{array}$ & 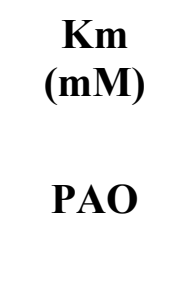 & 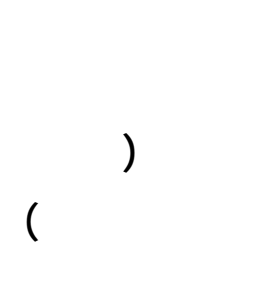 \\
\hline \multicolumn{7}{|c|}{ المتغيرات الحركية لأنزم PAO المق من ثم النساء للسليمك } \\
\hline تنافسي & 24.18 & 0.02 & 0.02 & 142.85 & 45.45 & 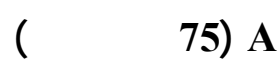 \\
\hline تنافيوي & 45.81 & 0.02 & 0.02 & 125 & 45.45 & (125)B Bلي.مولار) \\
\hline \multicolumn{7}{|c|}{ المتغيرك الحركية لأنزم PAO المق دن م النساء المصلبلت بلسكر نوع } \\
\hline تنافهي & 10.60 & 0.025 & 0.025 & 200 & 41.66 & A (50.50.aولار) \\
\hline تنافلي & 16.86 & 0.025 & 0.025 & 250 & 41.66 & B B (100ملي.100) \\
\hline
\end{tabular}

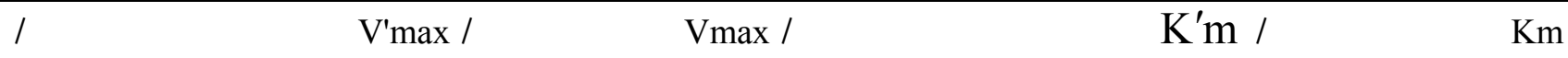

\section{المصادر المرسية}

الجبوري،طارقسليمان محمود علي (2002). خصائص أنزيم بولي أمين اوكسيديس وعلاقته مع فيت أمين

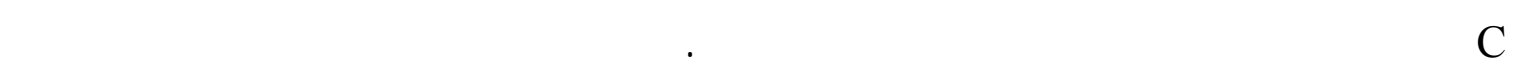
الموصل.

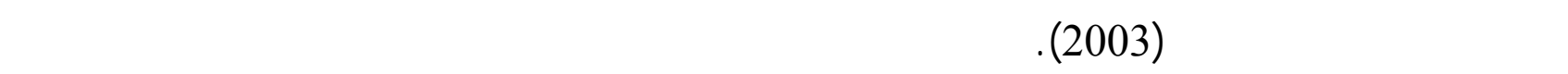
ولمسيديس المفى جزيئياً من للسائل اللشوكي عند الألفال المصابين بالتهابل المحايا البكتيرية. رسالة ملجبستير، كلية التربية، جلمعة الموصل.

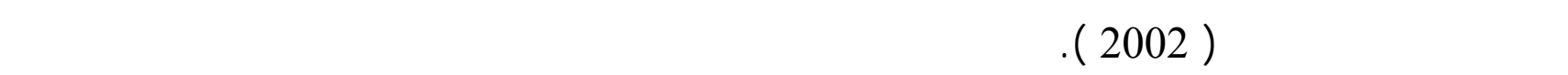

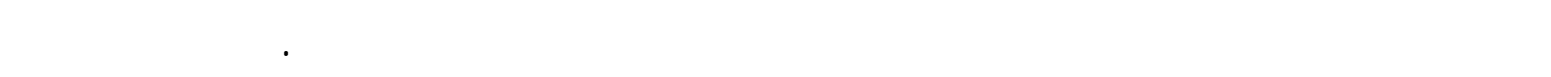
كلية التربية، جلمعة الموصل.

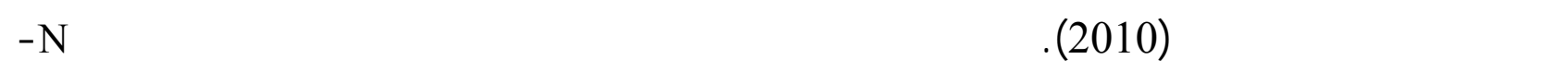
بنزوالبل ثايويوريا. بسالة ملجستير، كلية التربية، جلمعة تكريت.

\section{المصادر الأجنبية}

Rapoport, S.M.; Schewe, T.; Wiesner, R.; Halangk, W.; Ludwig, P. (1979). The lypoxygenase of Reticulocytes. Eur. J. Biochem., 99, 545-561. 


$$
\text { خولة لحمد آل فلبح ولخرون }
$$

Cohen, L.F.; Lundgren, D.W.; Farrel, P.M. (1976). "Polyamines". Blood, 48, 469-475.

Cona, A.; Rea, G.; Angelini, A.; Federico, R.; Tavladoraki, P. (2006). Functions of amine oxidases in plant development and defence. TRENDS in Plant Science. 11(2), 8188.

Dahel, K.; Flayeh, K.A.; Al-Saffar, N.M. (2001). Polyamine oxidase activity in Sera of depressed and schizophrenia patients after ECT treatmen. Neurochem. Res., 26(4), 415-418.

Flayeh, K.A. (1988). Spermidine oxidase activity in serum of normal and schizophrenic subjects. Clin. Chem. 412, 401-403.

Flayeh, K.A.; Wullace, H.M. (1991). Polyamine oxidase activity in a human colonic carcinoma cell line. Biochem. Sco. Thans., 18, 1225.

Gimenez, M.C. (2010). Development and use of tools to study metabolic consequences of altered polyamine catabolism. Ph. D. Thesis, University of Eastern Finland.

Jalkanen, S.; Salmi, M. (2001). Cell surface monoamine oxidases: enzymes in search of a function. EMBO. J. 20, 3893-901

Matcheroulx, P. (1999). UV-Visible spectroscopy as a tool to study flavorprotein. Methods in Molecul. Biol. 131, 1-7.

Méndez, D.; Aguilar M.; Méndez-Valenzue, V. (2007). Polyamine Oxidase Activity in Women with Preeclampsia-Eclampsia. World Applied. Sci. J. 2(3), 184-189.

Mendez, J.D.; Zarzozo, E. (1997). Inhibition of Platelet Aggregation by L-Arginine and Polyamines in Alloxan treated Rats. Bioche. and Molecular Biol International, 43, (2), 311-318.

Murray, R.K.; Granner, C.K.; Mayes, P.A.; Rodwell, V.W. (2009). "Harpers' Biochemistry". 28th ed., Appleton and Lange, USA, pp.155-156, 254-265, 332.

Murray-Stewart, T.; Wang, Y.; Devereux, W.; Casero, R. A.J. (2002). Cloning and characterization of multiplehuman polyamine oxidase splice variants that code for isoenzymes with different biochemical characteristics. Biochem J., 368, 673-677.

Robyt, F.J.; White, J.B. (1987). "Biochemical Techniques". Theory and Practice. Brookes/Cloe Publishing Company, Monterey, California, pp. 115-118,135-143.

Schacterle, G.R.; Pollack, J.K. (1973). A simplified method for the quantitative assay of small amount of protein in biological materials. Anal . Biochem., 51, 654-655.

Seiler, N.(1995). Polyamine oxidase properties and functions. Prog. Brain Res., 106, 333344.

Seiler, N. (1987). Functions of polyamine acetylation. Can. J. Physiol. Pharmacol., 65, 2024-2035.

Sjoholm, A.; Arkhammar, P.; Berggren, P.; Andersson, A. A. (2001). Polyamines in pancreatic islets of obese-hyperglycemic (ob/ob) mice of different ages. Am. J. Physiol. Cell Physiol. 280, C317-C323.

Wallace, H.M.; Fraser, A.V.; Hughes, A. (2003). A perspective of polyamine metabolism. Biochem. J., 376, 1-14. 